\title{
PARALELISMOS LEXICOS EN LOS DIALECTOS CATALANES
}

\author{
A mi profesor, Dr. Antonio \\ M. Badia Margarit.
}

InTroducción. CONCORdANCiAS LÍXICAS (I).

\section{P'Ritinuinar.}

I a buena acogida que algunos lingüistas dieron, hace años, a nucstro trabajo, aún embrionario, sobre "Las coincidencias léxicas entre el mallorquín y el catalán occidental", nos impulsó a tratar este tema con más amplitud y profunclidad.

Confesamos que en la elaboración del presente trabajo hemos chocado con graves dificultades, de orden diverso. Las concordancias estudiadas son esencialmente de carácter léxico, aunque, como veremos, no hemos podido evitar la inclusión de algunos caracteres fonéticos y morfológicos, por venir a corroborar algunas de nuestras conclusiones. E1 trabajo es, pues, fundamentalnente léxico y aquí reside la primera dificultad. Las áreas léxicas son, a menudo, tramas complejas en las que se entrecruzan vocablos dispares, de naturaleza heterogénea, sin ofrecer una clara uniformidad en cacla región dialectal. $Y$ es que el léxico es de esencia escurricliza, novible y se abre paso con facilidad en dominios extraños, bastándole para cllo uni pequeña circunstancia, micntras que los procesos fonéticos, por ejemplo, necesitan más tiempo para abrirse camino y triunfar.

Otra dificultad se refiere a los instrumentos de trabajo ${ }^{1}$. Sabida es la

1 Las obras citadas con más frecucncia, con las abreviaturas bibiográficas correspondientes, van al final del trabajo. 
utilidad de los Atlas lingülsticos para los estudios de Geograffa Lingüistica. Desde Gilliéron están prestando magníficos servicios a la investigación cientifica. Recordemos que un Atlas lingiilstico, el Sprach11nd Sachatlas Italiens und der Sïdschweiz ha sido la base del importante artículo de G. Rohlfs sobre Las coincidencias lingiiisticas entre Cerdeña y la Ilalia meridional y de tantos otros ${ }^{1}$. En Cataluña, como en el resto de Iispaña, no hemos sido afortunados con los Atlas lingüísticos. Iil Allas Lingiiistic de Calalnnya, de A. Griern, quedó inçoncluso ${ }^{2}$ y los nateriales desaparecieron con la guerra civil. A pesar de todo, hemos podido aprovechar algunos de los mapas publicados, que contienen cartografiados vocablos que son objeto de nuestro estudio. No obstante, la mayor parte de léxico, cuya distribución interesaba ver en los mapas para comprobar más exactamente las áreas coincidentes, no ha podido ser objeto de dicho análisis ${ }^{3}$. Tampoco hemos podido aprovechar los datos referentes al dominio catalán del Allas Lingiiistico de la Pentusula Ibírica, dirigidu por 'l'. Navarro 'l'omás, por haberse retrasado su publicación.

A falta de Atlas nos hemos acogido a las monogralias dialectales publicadas hasta el presente, las cuales van reseñadas en la Bibliografía o bien se citan en el curso de este trabajo. Iis lástima que no las poseamos en uúmero más crecido, a base de señalar la vitalidad de las palabras reunidas, así como los sinónimos que las rodean.

De gran utilidad nos ha sido la consulta del Diccionari Catald-valencidbalear, de Alcover-Moll, especialmente de los volúmenes publicados desde que se reemprendió la edición. İn los dos primeros y parte del tercero", no siempre queda clara la distribución del léxico en las distintas áreas dialectales. De todas formas hemos de reconocer que, sin su consulta, nuestro trabajo hubiera sido de elaboración muy difícil, por no decir imposible.

Ante la dificultad de recorrer personalmente las comarcas estudiadas,

1. RonLris, Sprachliche Bcrïhrungen zwischen Sardinien und Süditalien' Romanica Helvetica, IV (1937). 'Traducido al español y agrupado con otros articulus del mismo autor, reunidos con cl titulo de Listudios de Geografia Lingüistica de Ilalia, Universidad de Granada, 1952, pp. 165-264.

: lil últino mapa cs el 858 (/regar [la roba]).

3 Los méritos y defectos del $A L C$ han sido señalados por M. Sancins GuArNink cu su conunicación La Carlografia Lingüistica Catalana, "VII Congreso Internacional de Lingüistica Románica*, Barcelona, 1955, pp. 648-654.

- Por mediar un buen espacio de años entre la publicación de éstos y los que le han seguido. Nos commuica el señor Moll que dichos tomos scrín publicados de nuevo con las correccion es y adiciones pertinentes. 
para recoger "in situ» las palabras de interés, hemos aprovechado la presencia en Barcelona de personas procedentes de las zonas occidentales, con las cuales hemos realizado encuestas que han dado buen resultado ${ }^{1}$. No desconocemos los inconvenientes que presentan las encuestas llevadas a cabo lejos de la localidad a la que pertenece el informador. Crcemos, no obstante, que, cuando se trata de sondeos puramente léxicos, el peligro de acumular materiales falsos se reciuce al mínimo.

Por ser el mallorquín nuestra habla vernácula, nos hemos servido de su léxico cono punto de partida para nuestro estudio comparativo. Hemos llegado al conocimiento de los otros dialectos baleáricos a través de narraciones escritas. en cada modalidad insular o de monografías, tales como la excelente de $\mathrm{F}$. de B. Moll sobre la fonética y el léxico de Ciudadela (Menorca).

Siendo éste un trabajo sustancialmente léxico, hemos prescindido de señalar con transcripción fonética las variedades que toman los vocablos en cada área. In los casos en que hemos creido necesaria dicha transcripción nos hemos servido del sistema que el Dr. Antonio M. Badía Margarit expone en su Gramálica histórica calalana, que es una adaptación al catalán del de esta revista.

linalmente, no queremos cerrar este Preliminar sin hacer patente nuestro efusivo agradecimiento a cuantos nos han ayudado de una $u$

1 Helas aqui, con las abreviaturas con que aparecen en el texto:

Balaguer. Informador: señorita Marla Dolores Villalba, natural de la localidad. $-(=E V)$.

Benicarlo. Encuesta realizada por cl profesor M. Alvar y puesta amablemente a nuestra disposición. $-(=E A)$.

Les Bordes. (Valle de Arán). Informador: Don Fipólito Socasau, de diecisiete años. Ha vivido casi siempre en el Valle de Arán.- $(=E S)$.

Ddnia. Incuesta hecha con el señor Gadea Catalá, de veinte años, en Palma de Mallorca a donde se trasladó para efectuar el servicio militar. Había salido poco de su localidad.-(= EG $)$.

Lérida.-Informador: Don Ramón Feliu Domingo, de veintiocho años. Es natural de Alguaire - pueblo que dista unos I $_{5}$ kilónctros de la capital-, pero Lasta los veintisćis años ha vivido en I ćrida.- $=E F)$.

Oliana.-Informador: Don Iraucisco liscaler Calva, de veinticinco años.$(=E E)$.

Ulldecona. Informadores: Don Agustiu Roig Dominech, de cuarenta y siete años, y doña Mercedes Obiol 'Trabal, de cuarenta y seis. Naturales de diclaa localidac. Aunque desde I939 vivan en Barcelona, son conocedores perfectos de su habla.- $-E R$ (=E).

Valderrobres.-Informador: Doña Filomena Iounbarte Vallés, de cincuenta aũos. Desde lace años vive en Barcelona, pero conserva el habla de su pueblo natul. $-(=E L)$. 
otra manera a desbrozar el camino de nuestra investigación. Hemos de citar en primer lugar al Dr. Antonio M. Badia Margarit, que nos ha orientado por vías luminosas con sus sabios consejos, ha puesto a nuestra disposición todos los instrumentos de trabajo que estaban a su alcance y no ha dejado de alentarnos en ningún monento. D. Francisco de B. Moll ha tenido la amabilidad de dejurnos consultar algunas fichas cle $\mathrm{la}$ "Calaixera" de su Diccionari, o bien nos ha enviado información sobre vocablos que, en el momento de redactar nuestro trabajo, todavía no figuraban en los tomos publicados. Lil Dr. G. Colón y el Dr. G. Haensch nọs han permiticlo la consulta de sus tesis doctorales, todavia inéditas, sobre el vocabulario castellonense y sobre las hablas ribagorzanas, respectivanente. Iil Dr. Ii. Mateu y el Sr. M. Sanchis Guarner nos han informado sobre los dialectos valencianos; el Dr. Casas Homs, sobre los del Camp de 'arragona, y la Srta. A. Moll, sobre los de Ibiza. Debemos al Dr. M. Alvar otras notas interesantes, así como una encuesta sobre cl liabla de Benicarló ${ }^{1}$. Nuestra gratitud a todos cllos y a los informadores ya citados, yue, con las respucstas a nuestro cuestionario, han contribuido a hacer más precisas la extensión y vitalidad de cicrtos vocablos en las áreas occidentales.

Estructura.-Nuestro trabajo consta de tres partes: Introducción, Concordancias léxicas y Análisis e interpretación.

Ińn la Introducción justificamos el título ( $(\mathrm{I})$, especificamos los criterios empleados para la diferenciación en dialectos orientales y occidentales (\$ 2) y revisamos la posición del mallorquín ( $\$ 3)$. Añadimos después los caracteres fonéticos $(\S 4)$ y morfológicos $(\S 5)$ que acercan el balear al catalán occidental y lo apartan del central, para acabar planteando el problena de la afinidad de aquellas dos áreas en el campo del léxico $(\S 6)$.

Iin la segunda parte, despućs de exponer el criterio de que nos hemos valido para agrupar los vocablos coincidentes $(\S 7)$, presentamos una lista de los mismos, clasificados por grupos lógicos ( $\$ 9)$, a la que sigue un estudio monográfico de cada término (\$§ I0-I58).

Ein la tercera parte analizamos el carácter de la oposición léxica de nuestras áreas con la central: si es propiamente léxica, semántica, fonética o morfológica ( $($ I59), y con qué regiones del catalán occidental son más frecuentes las coincidencias ( $\S \mathrm{I} 60$ ). Prescindimos, como ajenos al

1 I,as nbrevinturas que adoptamos para señalar la procedencia de la información son las siguientes: Alvar (Inf. A); Casas Homs (Inf. C); Mateu (Inf. Ma); A. Moll (Inf. M); Sanchis (Inf. S). 
problema estudiado, de los vocablos cuya acepción coincidente puede ser ocasional $\mathrm{y}$ haberse desarrollado independientemente en cada área ( $(16 \mathrm{I}$ ). Comenzamos después un análisis de los factores históricos ( $\mathrm{I62}$ ) para comprobar su posible influjo: el sustrato mozárabe ( $\S 163$ ), la dominación musulmana ( $(I 64)$ y la colonización cristiana ( $(165)$, con una breve alusión a los mallorquines que se trasladaron a Alicante en el siglo xvir ( $\$$ I66). Buscando una solución más satisfactoria, acudimos a la teoría de las áreas de Bartoli, de cuyos principios hacemos una exposición ( $\S$ I69) para aplicarlos al dominio catalán ( $($ I7O). Distinguimos áreas aisladas ( $(I 7 I)$, laterales ( $(I 72)$ y posteriores ( $(173)$, que se caracterizan por su tendencia conservadora-con naturales limitaciones, especialmente en el valenciano ( $(I 7 I)$-, frente al área media, el catalán central, que, en muclios casos, irradia sus innovaciones de orden diverso ( $\S$ I75-I8I). Hacemos también una alusión al papel que han tenido los dialectos periféricos e insulares en el restableciniento de la lengua literaria ( I 82) y una comparación de algunos arcaísmos baleárico-occidentales, con los correspondientes tipos léxicos de las lenguas galorrománicas ( $\$$ I83). Iinalmente resumimos el resultado de nuestro estudio ( $($ I85).

\section{IN'TIRODUCCION}

I. Justificación de 1 tít u 1o.-Antes de profundizar en el tema, creemos urgente concretar y definir el título del presente trabajo. "Paralelismos léxicos en los dialectos catalanes» es un título amplio. y un poco vago. Permítasenos una explicación.

En muestra obra pretendemos estudiar esencialmente las concordancias léxicas entre el balear y el catalán occidental, es decir, entre dos conjuntos de dialectos bien definidos. Ahora bien: siempre que el rosellonés y alguerés participan de las mismas formas, constituyendo en aquellas áreas un bloque opuesto a las unidades lingüísticas del catalán central, lo señalamos para extraer argumentos reforzadores de nuestra tesis. Así se explica que un trabajo que estudia e intenta explicar los paralelismos de los dialectos balcáricos y occidentales, por la circunstancia expuesta pueda presentarse bajo un título a primera vista tan amplio.

La comparación es, sobre todo, de carácter léxico. Pero ello no nos la eximido de presentar algunos tratamientos de orden fonético y morfológico, comunes a nuestras áreas, por el interés que ofrecen para nuestra intexpretación general de los hechos.

Cuando hablamos de "catalán occidental", siempre que no se observe lo contrario, usamos el abjetivo en su acepción amplia, es decir, no sólo refiriéndonos al leridano y demás dialectos de la parte principal de 
Principado, sino incluyendo también todo el valenciano y el tortosino. Como veremos en su lugar, son más numerosas las concordancias del balear con estos dialectos que con el propiamente llamado "catalán occidental".

2. I a fragmentación dialectal de1 catalán: dialectos orientales y dialectos occidentales.I os dialectos que constituyen el dominio catalán se reparten en dos grandes áreas, claramente delimitadas y con fisonomía propia, que, desde Milà y Fontanals, han veuido llamándose catalán oriental y catalán occidental. El primero abarca las provincias de Barcelona y Gerona, parte de la de 'Tarragona, el Departamento de los Pirineos orientales y las Islas I3aleares; el otro comprende los Valles de Andorra, la zona oriental de Aragón, casi toda la provincia de I,érida, parte de la de Tarragona y el reino de Valencia ${ }^{1}$.

Son varios los criterios diferenciadores de estos dos grupos de dialectos. Veámoslos, siquiera sea sucintamente, para ver en qué grupo queda incluido el balear:

a) Tratamicnlo de a, e cilonas.-Se pronuncian e neutra en catalán oriental, micntras que mantienen su timbre diferenciado en el occidental.

b) Trataniento de è tónica. - Eùn catalán occidental se conserva en general como ę cerrada y en oriental pasa a e abierta.

c) Pronunciación de o, $\mathrm{u}$ cilonas. - Se confunden en $\mathrm{u}$ en el oriental $y$ se diferencian claramente en el occidental.

3. I, a posición del ba lear.-A pesar de la lomogeneidad que, en los rasgos gencrales, presentan los dialectos baleáricos, a veces uno de éstos difiere de los demás. Veamos si los criterios fonéticos, antes enumerados, nos sirven para situar el balear ell el grupo de dialectos orientales:

a) I a $a$ y la $e$ átonas se relajan en balear, pero el mallorquín presenta algunas excepciones respecto a la conservación del timbre de e cerrada, que tiene lugar: I) Ėn los derivados de vocablos primitivos, en que la $e$ tónica era cerrada o abierta: peu pẹ́u, penet pẹwḉt; bé bẹ́, benet bẹnét ${ }^{2}$. 2) En las formas verbales, cuyas rizotónicas tienen $e$ : pecar pẹká

1 Sobre la división, fronterns y dialectos del catalín oriental y occiucntal, consúltense: P. BAkNiLs, Els dialectes catalans, BDC, VII, 1919, pp. I-10; $\mathrm{F}$. DE 13. MoI,I, Gram. hist. cat., pp. I8-2.j; $\Lambda$. BADí, Gram. hist. cat., \$\$ 20-22; A. GruTiRA, Gramditica historica del caluld antic, 1931, I I-I 7 .

- Vid. A. Al.Covin, Una mica de dialectologia catalana, BDLL, IV, p. 226.

Recientemente hemos estudialo el problema de la e átona mallorquina en Noles phomefripues sur le parlir de Cumpos (Majorgue), comumicación presentada en el 'IA' Congrìs Intcrnationale de Iinguistique Romane (Lisbonne, I959)' $y$ qua aparecerá en el tomo de Actas y Memorias. 
(por analogia de jo pec, tu peques, etc.), frente a cat. or. peká; deixar, dęs̆á frente a cat. or. dẹš́. En este último caso, como en todos aquellos cuya $e$ tiene como vecina una consonante palatal, ésta puede haber coadyuvado al mantenimiento del timbre cerrado de la $e$, aunque la causa eficiente sea la analogía verbal. 3) Por último, en las palabras de origen erudito: Jelicitar fẹlisitá, especial ẹspẹsiạal, etc. ${ }^{1}$. L'ero éstas no son objeto de nuestra consideración.

b) Respecto al tratamiento de ē tónica latina, parte del menorquín y algunas localidades mallorquinas e ibicencas, van con el catalán oriental, por evolucionar a é abierta. İ́n cambio, casi todo el mallorquín y parte del menorquín e ibicenco conservan el sonido de é neutra, que habría sido propagado por la Reconquista ${ }^{2}$. La evolución a é abierta en el resto del Archipiélago es relativamente noderna, pues al principio del siglo $\mathrm{xIx}$ sólo se conocla la ć neutra en todas las islas ${ }^{3}$.

c) La confusión fonética de 0, la realizan el menorquín y el ibicenco, como el catalán oriental. Pero en Mallorca, sólo una localidad, la de Sóller, sigue dicho tratamiento. Lil resto de la isla las pronuncia diferenciadas 4 o bien, según lás regiones, sólo cierran en $u$ la $o$ átona que va seguida de $\ell$ o $i$ acentuadas: conill kuni, comi kumu. Esta tendencia es frccuente en catalán antiguo ${ }^{5}$.

De la aplicación de estos tres criterios al balear se desprencle que éste fonéticamente se acerca más al catalán oriental que al occidental. Las únicas notas discordantes salen del mallorquín y, o son tratamientos parciales (conservación de e cerrada), o se deben a tendencias conservadoras (e neutra, distinción de $0, u$ ), que le dan en parte alguna afinidad con el catalán occidental. Pero ¿son éstas las únicas afinidades fonéticas baleárico-occidentales?

4. Algunos caracteres fonéticos comunes al b a l e a r y cat a lán oc cide nta l. - Además de la conservación de $o$ átona, hay algunos otros fenómenos fonéticos que se dan única-

\footnotetext{
1 Ibidem.

2 H. IKUE, El El dialecto de Alguer y su posición eil la historia de la lengua calalana, "Anuari cle l'Oficina Romànica de Lingülstica i Literatura", VII, pp. I10-1 I2.

- I. Dxi B. Mor, Lial. Ciuladella, p. 4 or; fv. Gram. hist. cat., p. 73.

- li incluso pronunciando $o$ cn casos en que etimológicannente corresponde $u$ : bullir $b . \underline{l}$; justici $2 o s t i s i, c t c$. (Manacor, Palma).

- J. Coromnas, Las Vidas de Sanlos Rosellonesas del MS ${ }_{44}$ de Iarts, Anales del Instiluto de Lingiïslica de la Universidad de Cuyo, (Mindoza), III, 1943, p. 147.
} 
mente en el balear o en regiones del catalán occidental, mientras que hoy son desconocidos en el oriental. Examinémoslos brevenente:

a) Mantenimiento de $v$ labiodental, que se da en Baleares, reino de Valencia (menos el valenciano "apitxat»), Camp de Tarragona, Priorat y Alguer ${ }^{1}$. Dicha articulación debió de ser general en todo el dominio catalán, como lo fué ell el castellano, según ha demostrado A. Alonso en su excelente obra sobre historia de la pronunciación ${ }^{2}$. Las áreas citadas, al distinguir la articulación labiodental de $v$ de la bilabial de $b$, se muestran más conservadoras, más fieles a la lengua antigua.

b) Los grupos T'L, D'L, J'L y $G^{\prime} L$ evolucionan a $\mathrm{tl}$, pronunciado o I en balear, valenciano y tortosino ${ }^{3}$, mientras que se palatalizan en catalán oriental: s p a $\mathrm{t}(\mathrm{u})$ l a $>$ espatla espáltẹ frente a cat. or. espatlla espállẹ (véase maja núm. I).

In catalán antiguo aparece casi constantemente la grafía $t l$, tanto para los derivados de 'I'I, y D'I, (espatla, ametla), como para los de J'I, (balle). Se ha supuesto que a esta misma grafia correspondian dos pronunciaciones diferentes, th en el primer caso y !l en el segundo, y que unos dialectos habrían generalizado aquella pronunciación, mientras que otros habrían preferido la palatal 4. In el catalán oriental la extensión de la articulación palatal a casos no etinológicos (como los procedentes de T'L, D'L) debió realizarse en época relativamente temprana, a juzgar por las grafías provenzalizantes que $M$. de Riquer registra en Guerau de Massanet, poeta catalán del siglo xv: amenlha y ametlha, cctlha, vellha ${ }^{5}$.

c) Conservación de la -t de los grupos finales -nt y -1t. Dicha - $t$ final

1 Vid. Ar.covir, BDLLC, IV, p. 297; BARnirs, Die Mundart von Alacant. Beitrag fur Licnntnis des Valencianischen. "Biblioteca Filològica de l'Institut de la Lengua Catalanan, Barcelona, 1913, $\$$ 40, 43, 44, 78, 82, 83, 161, 163; GriLRA, El valencid, $B D C, I X$, I921, p. I3; MOLI, Gram. hist. cat., p. I05; BadfA, Gram. hist.cat., §67, II.

- A. Alonso, De la pronunciación medieval a la moderiza en español, Madrid, 1955, I, cap. I. İl jucleo-español de Oriente, con su distinción de $v$ labiodental y $b$ oclusiva, refleja probablemente dicha etapa primitiva (véase nota 65 de la página 7I).

3 Vid. Barnirs, Die Mundart von Alacant, § 134; M. Sanchis Guarnirr. Gramatica Valenciana, València, 1950, \$ 75; J. Corominas, Las Vidas de Santos lioselloncsas, § 28; MoL.I, Grum. hist. cal., P. I 38 ; BADfA, Gram. hist. cat., § 94. II y III.

- V'id. Bavis, Gram. hist. cal., $\$ 94$, III.

- Marifin'di: Riquis, Ciabricl Ferrug y Guerau do Massanet, poclas calalanes del s. MV. Iistudio y edición. Bolethn de la Sociedad Castellonense de Culalia, XXVII, chaderno II, p. 176. 


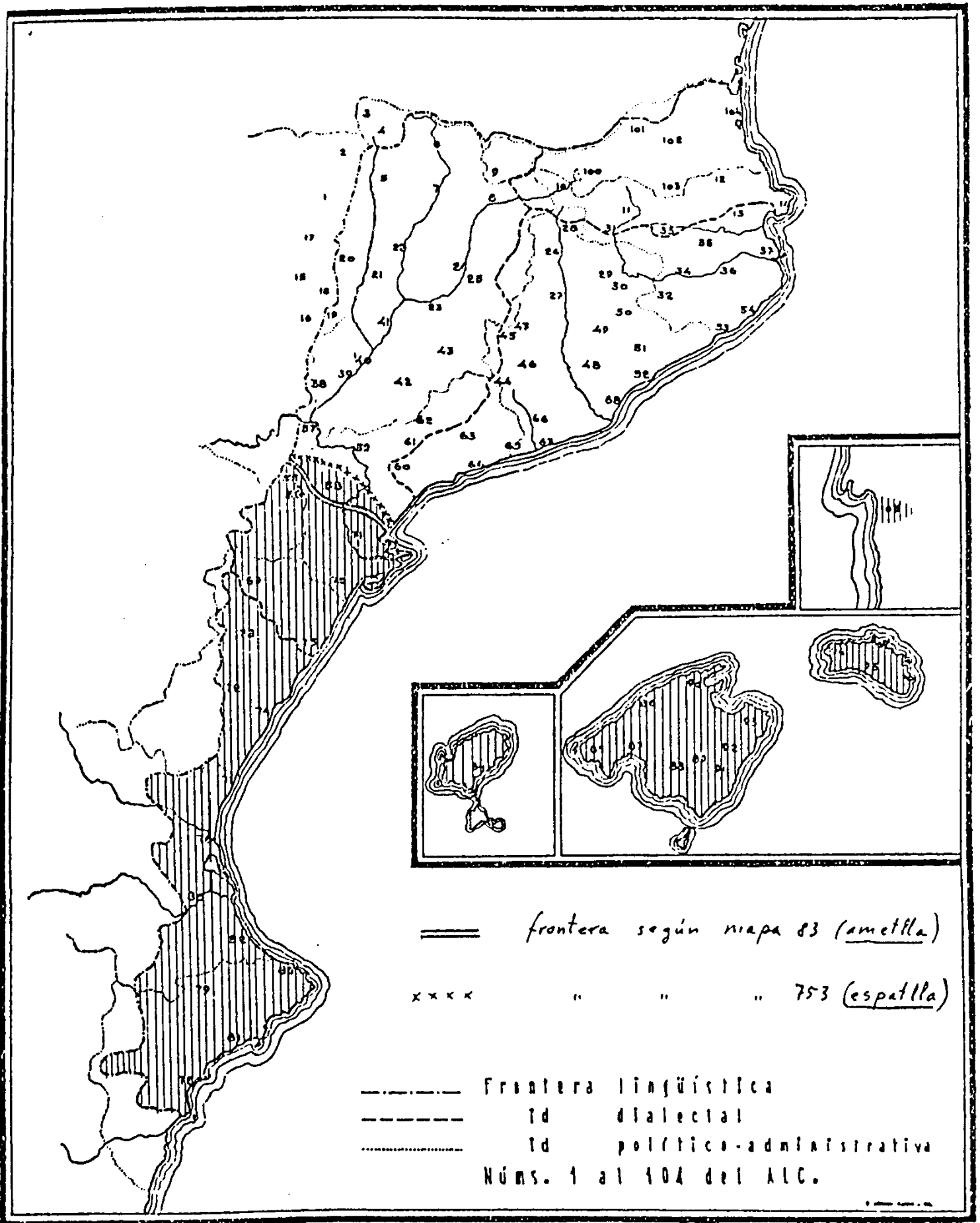

Derivados de $T^{\prime} L, D^{\prime} L, J^{\prime} L^{-} y^{\prime} G^{\prime} L$ sin palalalización (según $A L C$ ) 
es firme en el Principado hasta fines de la $\dot{\mathrm{E}}$ dad Media ${ }^{1}$ o quizá hasta más tarde ${ }^{2}$. Todavía hoy se percibe en Baleares y Valencia ${ }^{3}$, algunas veces en alguerés ${ }^{4}$ y cul las generaciones ancianas de Cardós y Vall

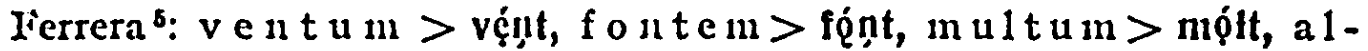
t $u \mathrm{~m}>$ ất. Lìn cambio, el grupo se ha simplificado en catalán oriental, y puede decirse que en todo el Principado, desaparecienclo la - $t$ : bę́n, Iọn, mọ́t, ạt.

d) Conservación del grupo $N^{\prime \prime} R$. En mallorqufn, menorquín ${ }^{\circ}$, ribagorzano $^{7}$, pallarés ${ }^{8}$ y toda la franja pirenaica del Principado ${ }^{\circ}$ se mantiene la articulación del grupo $N$ ' $R$ sin epéntesis y con $\overline{\mathbf{r}}$ vibrante múltiple, como en catalán antiguo: g e n e $\mathrm{r} \mathbf{u}>$ genre (cat. cen. gendre), c i n e r e $>$ cenra (cat. cen. cendra), etc.

Este arcaísmo, como se ve, no es exclusivo de las áreas occidentales, sino que se extiende al rosellonés, dialecto que, según veremos (§ 160$)$, se aparta, cu algunos de sus rasgos léxicos, del catalán central para unirse al occidental y, particularmente, al balear.

c) Ja abcrlura de e $y$ o. Caracteriza, en general, las hablas valencianas y balcáricas la doble abertura, en determinados casos, de las vocales $e$ y 0 , mayor que las del catalán del Principado: térra, pók, etc. ${ }^{10}$.

Algunos vocablos, además, presentan una 0 de abertura anómala en nuestras áreas. Es el caso de por < pa vore $n$, que ha conservado la en catalán y algunas zonas del Pirineo occidental ${ }^{11}$, mientras que en balear, valenciano y parte del catalán occidental ha pasado a pronunciarse abierta (pór, pó). Dicho cambio de timbre debió operarse en época relativamente temprana, a juzgar por el refrán que ya aparece en Tirant lo Blanc (s. xv): "Del mal que hom té por, d'aquell se mor», donde la 0

1 Coromnas, Vidas de Suntus Rusellonesas, pp. I55-156.

- Ibidem, nota de la p. 155.

- BARnis, Die MIundart von Alacant, $§ 87$.

- Morosi, Dial. Cat. Alghero, § 87 .

- Corommes, Cardós, § rg.

- Este dialecto of rece vacilación entre -n1r- y -ndr- (véase Ir. DE B. Mòli, Dial. Ciutadella, p. 48).

- La seizra en Bisaurri, Renanué, Espés, Bonansa, Noales y Ardanuy (HAzNSCH, p. 85$)$.

- R. Viotant y Sinorra, La terminologia de l'individu en el Flamisell, Miscel-lùnia Fabra", p. 29I; Corourntes, Cardós, § 29.

- Véase, en general y para otros detalles, Corominas, Vidas de Santos Rosellonesas, p. 154-155 y A. BADfA, Gram. hist. cat., § 92.

10 Vid. T. Navarro 'lomils y M. SANCuIS Guarnitr, Andlisis fonelico del valcnciano licrario, RFE, XXI, 1934, pp. II 7 y 119.

2 Vid. $D C V B$, s. v. y l'. vit 13. MOL,L, Gram. his cat., p. 89. 
de por ya debía pronunciarse abierta para rimar con la de mor $<$ mor it, de abertura fonéticamente normal.

5. Algunos caracteres morfológicos comunes a 1 balear y a 1 catalán occidental.-A los paralelismos fonéticos pueden añadirse algunos otros de carácter morfológico, comunes al balear y a parte del catalán occidental, como son:

a) Las desinencias -am $y$-au del presente de indicativo de los verbos de la I. ${ }^{n}$ conjugación, conservadas en las Baleares, SO. y $\mathrm{N}$. del catalán occidental, Andorra, O. del Rosellón y Campnany (S. de los Pirineos) ${ }^{1}$ cantam, -au frente a cat. cent. cantem, -eu. En las Baleares es donde con más vigor se mantienen estas desinencias. Ein alguerés, sólo la segunda ${ }^{2}$ : En el catalán continental sufren la competencia de las formas centrales, barcelonesas -em y -ell, que se imponen progresivamente ${ }^{3}$. Cuando se hagan las encuestas del futuro Atlas Lingiiistic del Domini Català estamos convencidos de que podrán contarse con los dedos los puntos del catalán continental que hayan conservado dichas desinencias.

Por otra parte, scñalemos que las formas balcáricu-occidentales sou las únicas que aparecen en los clásicos catalanes y que ya en el siglo xv la desinencia -em se tenía por incorrecta: "evitar de dir nosaltres anem per anamin'4.

b) La desinencia -au de la $2 .^{\text {a }}$ persona del plural del imperativo, que se extiende en las mismas zonas que usan dicha desinencia para el presente de indicativo ${ }^{5}$. Cat. cen.: -en (canten).

c) Las desinencias -às, asses, etc., del imperfecto de subjuntivo, inantenidas firmemente en las Baleares $y$, no tanto, en el $N$. del valenciano y parte del catalán occidental, donde empiezan a alternar con las modernas, propias del catalán oriental -és, -essis, etc. ${ }^{6}$.

1 Vid. H. KUEN, El dialecto de Alguer y st6 posición en la hisloria de la lengua catalana, p. 65 y el mapa de la p. 66 con las áreas de la desinencia -am.

2 IKune, ob. cit., pp. 65-68; GuARnerro, Dial. cal. Alghero § 149.

a In algunos pueblos, las formas -am, -alt quedan vivas sólo en boca de los ancianos, mientras los jóvenes prefieren las modernas. En el año Igog se decia, al respecto, de la localidad de Borges Blanques: "Los vells acostumen encara a terminar ell -am, -au les dues primeres persones de plural sallam, sallau, anam, anau, etc., formes que es van perdent de cada dian (BDLLC, VI, p. 85).

- $\Lambda$. BaDfa, "Regles de esquivar vocables o mots grossers o pagesivols". Unas normas del siglo $X V$ sobre purcza de la lengua calalana. Boletin de la Real Academia de Buenas Letras de Barcelona, XXIII, I950, núm. I 68.

- Vid. ALC, maja núm. I05 aneu-vos-en, sobre el que se basa KUEN, ob. ril., p. 68 .

* Kulin, ob. cil., p. u\&. 
d) Algunas formas verbales aisladas. Ciertos verbos presentan en algunos tiempos y personas derivados que, en nuestras áreas, han permanecido fieles a las formas medievales, mientras que en el catalán oriental, en general, han sido arrastradas por la analogia verbal. No profundizaremos en este aspecto que no afecta esencialmente a nuestro trabajo, puesto que es léxico, pero citaremos dos ejemplos significativos.

La primera persona de morir era en catalán antiguo (jo) muir, normal fonéticamente por cuanto deriva del latín morio, y hoy es muy vivaz en balear $y$ en buena parte del valenciano, donde, a través de muir(c), ha pasado a miic (cat. cen. moro). Lo mismo sucede con las cuatro personas del presente de subjuntivo derivadas de moriam, -ias, -iat i a $n t>$ muira, -es, $-a$, -en (val. muiga < muirga), que ofrecen parecida distribución geográfica ${ }^{1}$.

E1 participio omplit, bajo leves variantes (omplit, umplit, amplit, aumplit, umprit), es característico del balear, valenciano, occidental, pirenaico-oriental y alguerés, mientras que la forma analógica omplert ha invadiclo casi todo el citalán central, con excepción de algunas localidades $^{2}$. Areas parecidas deben de ocupar los participios cstablit, complit, frente a sus equivalentes del catalán central esiablerl, complert.

e) Las terminaciones de plurales en -sts $y$-scs, usados en balear y gran parte del valenciano ${ }^{3}$, sin adición de vocal, como ocurre en el catalán oriental y la mayor parte del Principado (-stos, -scos): trists pron. trisŝ o triŝ, frente a cat. or. triştus; boscs pron. bọisks o bQ̣̂s frente a cat. or. bọjskus.

f) Uso de la forma pronominal vos en vez de us. Se extiende al balear, valenciano, tortosino y catalán occidental 4: vos dic frente a cat. or. us dic.

Todas estas características son propias de la lengua de los escritores catalanes nedievales.

6. Planteamiento de 1 proble na.-Acabamos de ver, a través de estas páginas, que, partiendo de los criterios fonéticos diferenciales que escinden el catalán en los dos grupos de dialectos señalados, la inclusión, en líneas generales, del balear dentro del catalán oriental

1 Vid. F. DE B. MoLI., La flexio verbal en els dialectes catalans, Auuari de l'Oficina Romànica de lingülstica i Literaturan, V, p. 56 y 57.

2 MOL.I, ob. cit., IV, p. 83.

- BARNILS, Die MItndart von Alacant, $\$ 35$.

- Josip Ginir, Els pronoms personals en valencid, Separata de l'Almanac - I.as Provincias", Valencia, $195^{2}$. 
es justa. Hemos visto, no obstante, algunos rasgos fonéticos, exclusivos del mallorquin, y otros morfológicos, de todo el balear, que se resistían a emparejarse con el catalán oriental y encontraban sus paralelos en el catalán occidental.

Con el léxico ocurre algo parecido. Iil gran caudal del vocabulario balcar-aparte las diferencias de los subdialectos-es el mismo del catalál central. Pero hay más de un centenar de vocablos usados en el balear que, inexistentes en el catalán central, reaparecen en zonas del occidental. Es decir, que el catalán central constituye muchas veces un bloque disidente frente a la extraña uniclad de aquellas dos áreas. ¿Cómo explicar tales concordancias, si sabemos que la gran masa de conquistadores y colonizadores que llegaron a las islas en el siglo xir pertenecía sobre todo a los dominios del catalán oriental? ¿Hemos de atribuirlas a las reminiscencias de algunos colonizadores allí establecidos, procedentes de comarcas occidentales? ¿İs suficiente esta inmigración de la Reconcuuista o liabrá causas de otro orden que expliquen esa parcial miclacl? IIe aquí brevemente expucsto el problema central de nucstro trabajo.

\section{CONCORDANCIAS I,EXICAS}

7. Criterio agrupador de coincidencias.-Esta parte de muestro trabajo-la más extensa - reúne todos los vocablos que hemos podido recoger que presentan formas paralelas en balear y occidental. Jero ¿por qué criterios nos hemos regido para considerar coincidentes dos vocablos?

Por lo que respecta al caricter de dichas coincidencias, hemos de tener presente las siguientes observaciones:

I) In principio, pretendemos reunir ejemplos coincidentes en balear y catalán occidental, que ofrezcan un tipo léxico opuesto al del catalán central. Arena, por ejemplo, frente a sorra.

2) Dado que estudiamos paralclismos en un mismo dominio lingüístico, consideramos coincidentes dos térninos cuando en las clos áreas comparadas poseen la misna acepción, mientras que en catalán central ésta es diferente. Así, calces 'medias' en oposición a mitges del catalán central, donde aquel vocablo equivale a 'pantalones', especialmente de la mujer.

3) Alora bien, cua do un tipo léxico se da únicamente en nuestras áreas, cono ocurre con los arabismos, pero con acepciones diversas en los varios dialectos que forman el balear y el catalán occidental, entonces 
lo inclufmos como paralelismo. Is el caso de albelló (cfr. $§$ roz), con su variedad de acepciones.

4) En nuestra agrupación inclufnos algunas palabras aisladas; cuya concordancia estriba en una idéntica evolución fonética que afecta a un rasgo esencial, como es, por ejemplo, la unánime conservación de la vocal tónica en coa $<\mathrm{cauda}$, frente a su cambio cle timbre en el catalán central cua.

5) Algunas veces establecemos la concordancia por la mayor vitalidad o frecuencia de uso de que es objeto un vocablo en nuestras áreas, frente al ejemplo caduco o, a veces, meramente literario que tiene en el catalán central. Es el caso de amollar ( $\S$ I35), que, a pesar de entenderse todavia su sentido en Barcelona, ha sido desterrado del lenguaje corriente; o bien de cercar ( $\S \mathrm{I} 36)$, usado siempre eu la lengua culta, pero sin ninguna vitalidad en la popular del catalán central, clonde ha sido sustituído por el castellanismo buscar.

Respecto a las cireas comparadas, conviene tener presentes algunas observaciones:

6) Repetimos que la denominación de "cialalán occidental» está tomada cn su acepción amplia.

7) Iil término coincidente puede, en el balear, ser exclusivo de una isla y, en el catalán occidental, de un solo dialecto, sea valenciano, tortosino o leridano. Así, dolent 'enfermo' es privativo de Ibi\%a en el Archipiélago y del tortosino y algunas otras localidades aislarlas en la Peninsula.

8) Siempre que el vocablo coincidente en balear y cataláı occidental reaparece en rosellonés o en alguerés, lo anotamos por lis razones que más arriba hemos apuntado (cfr. $\S$ I) y que más extensamente desarrollaremos en la última parte de este trabajo. Incluso, en tuos pocos casns, hemos registrado concordancias exclusivas del balear con el rosellonés y alguerés, sin que pretendamos considerarlas exluaustivas.

9) También indicamos si las concordancias se prolongan eli los dominios de las lenguas vecinas. No sólo nos detenemos en las localidades catalanas administrativamente emplazadas en territorio aragonés; sino también en las que son lingiuísticamente aragonesas. Iin las zonas fron'r terizas tienen lugar interferencias léxicas y préstamos mutuos, que han de tenerse muy en cuenta. I,o mismo hay que decir respecto al dialécto gascón que se habla en el valle de Arán. Al estar situado en territorio catalán, alguna ha de ser la contribución de los dialectos vecinos al léxico de las hablas aranesas. Además, el carácter arcaizante tanto del aragonés como del aranés son factores que nos ayudan en la interpretación general de los hechos. 
l'arecido valor cabe atribuir a las coincidencias con el léxico murciano "panocho" por la antigua colonización catalana que tuvo lugar en esta región, o con algunos vocablos de los dialectos sardos, llevados a acquella isla cuando la dominación catalana.

8. Observa cio nes.- Sigue a continuación la lista de términos coincidentes en las áreas indicadas, opuestos a los del catalán central. Los hemos ordenado por grupos lógicos, adaptando a las exigencias de nuestro vocabulario la clasificación que el profesor A. Badía Margarit. hace en su monografía El habla de Bielsa.

Cada vocablo, común a nuestras áreas, va acompañado de su traducción al castellano. Sigue el término opuesto del catalán central. A continuación, la etimologia, a la que siguen todas las árcas del balear y del catalán occidental en las que se registra el término estudiado. En cada caso se señalan, entre paréntesis o en nota de pie de página, las obras de donde procede cada localización. Añadimos también los numbres de las localiclades en cuy'as encuestas hemos registrado el vocablo en cuestión, de acuerdo con las abreviaciones que antes hemos indicado (p. 9.3 . notal I). Por último, presentamos una breve lista de auloridades clásicats que usan la voz en cada caso. Dichos términos van documcntados con citas antiguas procedentes del Diccionari Calala-Valcncici-ljalcar y, a veces, del Diccionario Aguiló, las cuales figuran en primer lugar, limitándonos a consignar el autor y obra, sin reproducir el fragmento del texto sino en contados casos. A estas citas juntamos otras que hemos recogido en nuestras lecturas de catalán antiguo. No ha sido nuestro intento proceder a una recogida extensa de ejemplos, sino que simplemente hemos venido a completar la información de las obras mencionadas, proporcionando en algún caso testimonios más antiguos que los que éstas citaban (cfr. § I35). Iistos ejemplos de nuestra cosecha van acompañados de su contexto para poder captar sus matices semánticos y evitar la sequedad del vocablo aislado.

Cuando el interés del vocablo asi lo exige, se hace de éste una breve monografía, en la que se tratan aspectos cronológicos respecto a la forma opuesta del catalán central, se relaciona con otros términos románicos afines, se hacen observaciones de detalle sobre matices de uso en cada región o sobre su popularidad o decadencia, etc. Ėn general, no prestamos atención a las variantes fonéticas, sobre todo si se deben a rasgos constitutivos de cada dialecto. Cuando la diferencia es notable, entonces la indicamos, a veces con la transcripción fonética (bescollada del valenciano, pronunciado baskolá, junto a batcollada del mallorquín; vero, del castellonense, al lado de ver, del mallorquín, ctc.) 
Con los datos proporcionados por el Allas Lingüistic de. Catalınya, de Mn. Griera, hemos confeccionado I7 mapas para distinguir más claramente las áreas coincidentes. $A$ veces hemos completado aquella información con los datos del $D C V B$ o con alguna monografía dialectal. Nuestra intención era ambiciosa respecto a los mapas. Queríamos hacer tantos como palabras estudiadas, pero ello ha sido imposible por las circunstancias a que al principio hemos aludido. Las muchas lagunas y la falta de precisión en la localización geográfica de algunos vocablos ${ }^{1}$ sólo podrán superarse con la publicación de un nuevo Atlas del dominio catalán y de otras monografías dialectales.

9. Clasificación por grupos lógicos.-lin el presente trabajo reunimos más de un centenar de vocablos, para cuyo estudio los hemos clasificado en dieciséis grupos lógicos, incluyeṇdo en un grupo aparte-el XVII-, bajo el título Varia, todos aquellos términos, especialınente verbos y partículas, que no eran fácilmente agrupables. In conjunto, son los que siguen:

I. La vida en la familia:

$\begin{array}{ll}\text { nin } & \text { fadri } \\ \text { comare } & \text { padrí } \\ \text { bres } & \text { cementeri } \\ \text { engronsar } & \end{array}$

II. Partes del cuerpo:

$\begin{array}{ll}\text { bescoll } & \text { caràcter } \\ \text { bescollada } & \text { garrit } \\ \text { morro } & \text { calcigar } \\ \text { besada } & \text { esgarronar } \\ \text { clau } & \text { llenegada } \\ \text { nirvi } & \end{array}$

III. Indumentaria:

$\begin{array}{ll}\text { capell } & \text { calçons } \\ \text { calces } & \text { faldetes } \\ \text { calcetins } & \end{array}$

1 Especialmente de los que no hemos podido consultar en el $D C V B$ o en el $A L C$. 
IV. Vida fisiológica y sensible:

becada

fredolec

V. Vida psicológica:

becar

becada

felló

pudent

VI. Vida religiosa:

missar

VII. Enfermedades y de/eclos /isicus:

dolent
bua
buranya, buanya
pigota
pigota borda
pallola

VIII. Vida social y comercio:

carrera

malnom

menuts talent

flastomar

modorro

magencar

desenes

rosa

tort

llosco

mostela

padrastre

vidriola

taüllar, traüllar

almut

IX. Oficios y cargos:
batlle
nuurada
calciner
llambroix

X. La casa: sus partes, ocupaciones domésticas, tililes:

$\begin{array}{ll}\text { escaló } & \text { esbajocar } \\ \text { galfó } & \text { granera } \\ \text { soll } & \text { agranar }\end{array}$




espalmador
espalmar
sollar
torcar
poal
burballa

XI. Alimentacion:

brossat
enclívia
cuscús, cuscussó
maçana
maçancra
xerec

XII. Accidenles geogrifficos:

$$
\begin{aligned}
& \text { arena } \\
& \text { coll } \\
& \text { davallada } \\
& \text { davallar } \\
& \text { marjal }
\end{aligned}
$$

XiII. El ticmpo almosférico:

calabruix

XIV. El ticmpo cronológico:

enguany

un any part altre

XV. Vida agricola y' pastoril:

fraula

bruixa

peramany

blat d'ludi

dacsa escombrar

fènyer

fenyedor

marguà

ventall

cordell borja

eixangucr

fes

fesser

gangalla banyar-se

baldauna

mullar

llépol

estovar-se

forqueta

cas

noll

blan

albelló

sort

primavera d'hivern

despusahir 


cas
coll de la palla
pallús
mosso

XVI. Animales:

ca

somera

aregar

mardà

porcastre visc

novell

guarda teulader, -1
baldana
morralla
gambosí
coa

XVII. Varia:

aidar
anollar
cercar
cinglar
cinglada
defendre
flixar-se, afluixar-se
fus
jas
jau
llevar
treure
parèixer

rallar

o!

davall

fa

manco

milanta

pus

qualcú

quelcon

redó

redol

ver, vero qualque

\section{La vida en la familia.}

Io. NIN, -A, 'niño, -a',-Cat. cen. nen, -a.-Etim.: del radical onomatopéyico n a n-, $n$ in - para designar cosas infantiles (DCVB).Areas: Mallorca; Rosellón (Grandó, Voc. rossellonès); Valencia (Escrig; M. Gadea, Dic. Gen.; Griera ${ }^{1}$ ); Borges Blanques (Griera, ob. cit.); Morella nina (DCVB); Sopeira nino, -a 'adolescent, xicot, -a' (Oliva, Cat. Sopeira); Benasque nina ${ }^{2}$; Benabarre nino 'chico' (Badía, Contrib.); Bielsa

1 A. GRIrrs, Triptic: la naixença, les esposalles, la morl, BDC, XVII, p. 87. - Cirs Gomis: La Vall de Venasch, Anuari de la $\Lambda$ ssociacio d'Lixcursions Catalann, II, 1882 (Barcelona, 1883 ), p. то5. 
ninno 'niño pequeño hasta que empieza a andar' (Badła, Bielsa); Arán nin 'muchacho' (Corominas, Voc. aran.).-Cat. ant. Muntaner, Crònica, cap. 96: "Podets acomparar a Gaspar que era jove e min»; Masdovelles, Lo Llibre de tres (s. XIV o xv) ( $D C V B$ ).

Nen no viene documentaclo en catalán antiguo. Iin cambio, sí que encontramos nin. Además, mina o nincta designando la 'pupila', general en todo el dominio, parece que debió su origen a nina 'niña', por la pequeña figura que se refleja en la pupila ${ }^{1}$. Esto es indicio de su antigliedad y de su frecuencia de uso. En el catalán central, min 'niño' ha sido desplazado por nen, de formación más moderna (vid. $D C E C$, s. v. niño), y aquél, en su forma femenina, ha pasado a designar la 'pupila' o la 'muñeca con que juegan los niños'. Resto de aquella denominación es nina major "la filla més gran que queda un cop s'ha casat la primera" (Griera, Tresor), cxpresión que se usa en Vic.

La vitalidad de $n i n$ se ha visto comprometida con la competencia de otros sinónimos incluso en parte de las áreas occidentales y baleńricas, donde han llegado a inponcrse: fict en Menorca; boix, garrit, gastia en Ibizal; minyó, minyonct, xic, xiquet en occidental.

II. COMARE 'comadrona'.-Cat. cen. llevadora.-Etim.: del lat. c o m m a t e r.-Areas: Mallorca, Menorca, Valencia (DCVB) 2 ; Onda (Dicc. Aguiló); Castellón (Colón, Voc. Cast.); Benicarló (EA); Ulldecona ( $E R$ ); Valderrobres ( $E L$ ); Denia (EG); comadre Fonz (Bosch, Voc. Fonz), Benasque (BDC, VI, p. 28), Bielsa (Badia, Bielsa), Bisaurri, Bonansa (Alta Ribagorza) (Haensch, p. 248).-Cat. ant.: Lo Somni de Johan Johan, ap. "Cançoner Satírich Valencià" (s. XV y XVI) publ. por R. Miquel y Planas, Barcelona, I9II, p. I06, v. 583: "Puix fou passat. hun bon espay - ab veu prou alta - una, mostrant estar malalta - crida: Comare: - ¿per reposarme yo la mare quey serà bo? - Senyora mía, per açò- (dix la madrina) yous hi daré prest medicina».

En catalán antiguo no es muy abundante comare con el sentido de 'comadrona'. Los términos más documentados para este significado son madrina y llevadora. El primero, atestiguado desde el siglo XIV, vive

1 Compárese el mismo proceso en pupila < lat. pupilla, femenino de pupil-

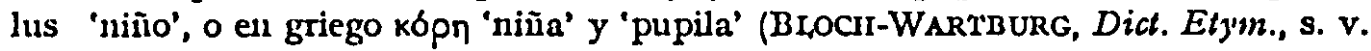
pupille).

2 Para Valencia, véase también M. Gadisa, Dicc. Gen. y recuérdese la expresión parcix la comari de Foyos, citada en Tipos, modismes y coses rares de la terra del ge arreplegades y ordenades per un aficionat, molt entusiasmat de tot lo d'ella [MIAKTI GADLA], València, I, p. 55. 
todavia hoy en '́ortosa y en varios puntos septentrionales de la Cataluña occidental ${ }^{1}$. Este significado debió desarrollarse a partir del de 'madrina', es decir, 'mujer que asiste a alguien que recibe un sacramento', común a las lenguas romances (prov. mairina, ital. madrina, fr. marraine). I'osiblemente comare 'partera' ha sufriclo un proceso semántico parecido, pasando de 'madre espiritual que cuida la criatura' a 'mujer que ayuda a nacer al niño'. In castellano aparece comadre 'partera' desde el siglo XVII ${ }^{2}$. Tanto en castellano como en parte del catalán comadre o comare significan, o han significado, "padrina de fouts d'un infant, en relació al padri o als pares d'aquest) ( $D C V B$ ).

El otro término de la lengua clásica que designa la 'comadrona' es llevadora, que se habrá formado sobre el verbo llevar 'levantar, sacar', aludiendo a la misión de la partera respecto al niño que va a nacer (compárese aranćs lewadii, lebadtira, prov. ant. levairitz ${ }^{3}$, ital. levatrice). Dicho término fué introducido por los catalanes en Cerdeña, donde cl dialecto campidanćs posce las formas levadóra, l'cvatora 4 . T'ambién fue usado en Mallorca, por lo menos hasta el siglo xvin, pues hay un documento de 1754 en que se atestigua el vocablo $y$ cn Süller hay una casa conocida por $\mathrm{Ca}$ Sa Llevadora, según los datos del $D C V B$. Además, en Ibiza ha sobrevivido la variante llevanera ${ }^{5}$.

I2. BRES 'cuna'. - Cat. cen. bressol. - Etim.: de la raíz b e rti 'mover, sacudir', probablemente gala; quizá postverbal de bressar, quizá regresión de bressol (cfr. berciolu, s. viII) $(D C V B)^{6}$. Rolulfs ${ }^{7}$, del examen de la difusión geográfica de las formas como bèr, bres, etc., deduce un substantivo céltico que podría reconstruirse bajo la forma * b e r $t$ i u o * b e r ciu, probablemente con el significado originario de 'cesta'.Areas: Baleares, Conflent, Listerri, Isabarri, Llavorsí, Vilaller, Sort, Pobla de Segur, 'Tremp, Tamarite, Balaguer, Lérida, I'raga, Borges Blanques, 'Tortosa, Morella, Vinaròs, Castellón ( $D C V B$; ALC mapa nú-

\footnotetext{
1 J. Corominlis, Cardós, p. 297, y $D C V B$, s. v.

2 S. GIII GAyA, Tesoro lexicográfico I492-1726, Madrid, I947, fasciculo III.

3. J. Coromunas, Voc aran. p. 80.

- M. I. Wagner, La lingua sarda. Storia, spirito e forma, "Biblioteca Romanicas, Berna, I 954, p. 232.

- Según $D C V B$.

- Para este problema etimológico, veáse WV. vON WARTBURG, FEW, s. v. * bertiare y $D C E C$, s. v. Urizo.

7 GIRHARD ROHLIS, Die lexikalische Differenzierung der romanischen Sprachen. Versuch einer romanischen Worlgeographie asitzungsberichte der Bayerisclien $\Lambda$ kadenic der Wissenschaftenn, Jalırgang 1954, Ileft 4, München, 1954, p. $5^{6}$, niapa 28 .
} 
mero 3I6) 2 , Catllar, Cocentaina ( $A L C$ ), Ulldecona (ER), Valderrobres (EL); Espés, Bonansa, Castanesa (Haensch, I88); E. de Murcia (G. Soriano, Voc. mutrciano); Oliana, Solsona y Formigueres bressa $(A L C)^{2}$. Véase mapa núm. 2.-Cat. ant.: R. Llull, Doctrina pueril: umés nou als infants lo bres que 1s plors»; Trobes en lahors de la Verge Maria; Inventario I5I7 (DCV B); Doc. 1430 (Dicc. Agililb).

Ėn catalán antiguo alternan bres y bressol, pero lo más probable es que la primera denominación sea la primitiva, pues bressol no es más que un diminutivo ${ }^{3}$, formado en época antigua (cfr. berciolu, s. virI), pero posterior forzosamente a bres. Basamos la mayor antigüedad de éste en varias razones: a) Bres tiene equivalentes románicos en la lengua antigua (fr. ant. bers, prov. ant. bres), o bien en formas actuales de lenguas y dialectos conservadores (port. berço, salmantino brizo, normando bers, etcétera) 4 .

b) Es casi seguro que bressol no es más que un diminutivo de bres por el hecho de estar en torno a las designaciones infantiles, en las cuales abuncla csta sufijación diuninutiva de carícter afectivo. Compárese el dininutivo bressol con el val. cuncla (mapa núm. 2) y el ital. dialectal cónnula y culla $<$ cunula, diminutivo de cuna ${ }^{5}$ y recuérdense diminutivos que, en relación con el mundo afectivo de los niños, han llegado a perder el valor de tales: leridano beset $<$ bes + suf. -et (vid. mapa número 5), 'beso'; cat. tiet 'tio'; noi < nin + suf. -oi 'muchacho, joven', si es válida la etimología propuesta por Moll (Supl. $\left.R E W 2^{2368}\right)^{\circ}$, etc.

De todas maneras, repetimos que en la época medieval coexisten las dos variantes e incluso las dos aparecen a veces en un mismo escritor (por ejemplo, R. Llull). En Alguer, a diferencia de las Baleares, se intro-

1 Algunas de estas localizaciones geográficas quedan confirmadas por monografias dialectales o por nucstras encuestas: Fraga (Barnirs, Cat. Fraga). Borges blanculues (R. Arquis, Varianls Borges, p. 39), Tortosa (Mísire, Voc. Torlosa), Castellón. (COL,ón, Voc. Cast.), Benicarló (EA), J,érida (EF).

- La información de Oliana, corroborada por encuesta.

s Vid. Blochi-Wartiburc, Dict. El''m. y G. Romlis, ob. cil.

- Para otras formas, véanse las dos obras citadas y, además, Corominas, $D C E C$

- G. RoHris, Estudios sobre Geografia Lingütstica de Italia, Granada, 1952, páginas 76-77.

- Se habja pensado en derivar noi del étimo no vi u . cuya evolución semántica viene apoyada por el significado de 'joven' que se ha registrado en el judeoespañol de Marriecos (vid. J. BliNon.Ini, Dialecto hispano-marroqui o hakita, BAE, IIV, p. 160 y M. Ar.VAr, Evilechas judeo-españolas, Granada, 1953, pp. 63, 82 У 179). Pero la evolución foncitica presenta dificultades. 


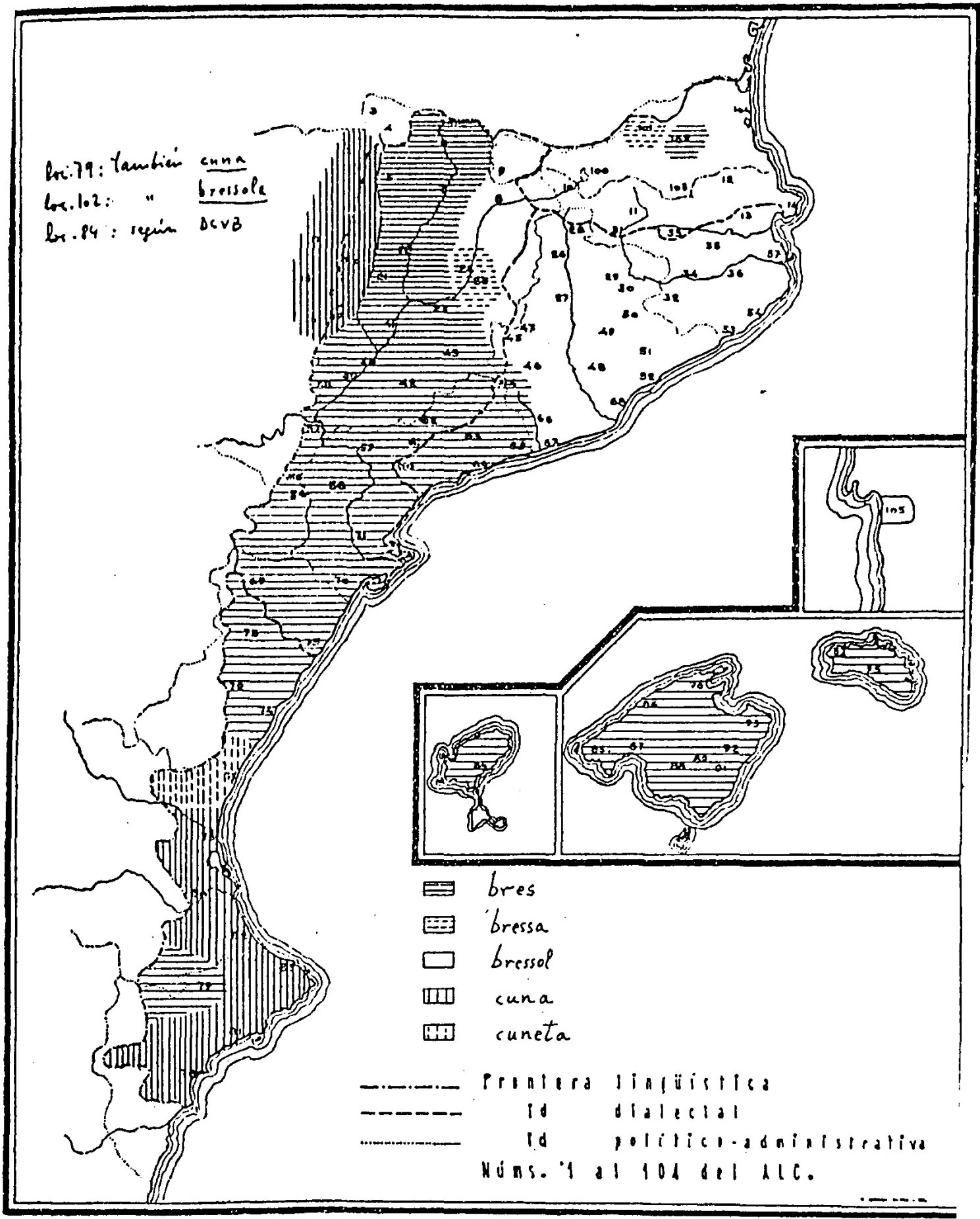

Las denominaciones de 'cuna' en calalán (scgün $A L C, 316$ )

s 
dujo la forma diminutiva lı brasol ${ }^{2}$ e incluso se extendió a los dialectos sardos bajo las formas bartsólu, brattsólu².

En el valle de Aneu, bres tiene el significado de "cistell gran de forma semblant a un bres d'infant, que serveix per traginar fruita $i$ verduran ( $D C V B)$, que se accrcaría al sentido que sugiere Rohlfs.

Bressa es una forma fomenina que tiene paralelos en algunos dialectos de la Galia ${ }^{3}$. Al S. del reino de Valencia, predomina el castellanismo cuna o su derivado, catalanizado, cuncta.

I3. ENGRONSAR, GRONSAR, 'mecer, mover',. - Catalán cen. gronxar. - Itim.: onomatopeya, según L. Spitzer, $B D C$, XI, II9; relacionado, según Wartburg, con el occitano crossar $<$ céltico crottiare; del céltico crontiare, según Corominas, $B D C$, XXIII, 295 (DCVB).-Areas: engronsar Mallorca 4, Castellón ${ }^{5}$, Alicante $(D C V B)$; Valderrobres (EL); gronsar Tor, Areu, Ferrera, Bellpuig, Benassal ( $D C V B$ ); Cardós y Vall İerrera (Coronines, Cardós); Macstrat (G. Cirona, Voc.), Ulldccona (ER). Benicarló (EA); asgrumusar Denia ( $E G$ ), Ibiza (Inf. M.); agrunsar Valencia, Valls (DCVB; $M$. Gadca, Voc. 30); argunsar 'mccer, columpiar', Murcia (Oriluela y su comarca), con sus derivadus argunsadcra 'columpio' y argunsón 'impulso y vaivén del columpio' (G. Soriano, Voc. Murciano).

El paralelismo de las formas aducidas es de orden puramente fonético y reside en la carencia de palatalización de la $s$, rasgo que, de aceptar cualquiera de las dos últimas explicaciones etimológicas, acerca nues-' tro término a la hipotética base primitiva y a sus probables parientes románicos (comp. prov. crossar).

Sobre ninguna de estas variantes tenemos información documental antigua.

I4. FADRI, -INA 'soltero'.-Cat. cen. solter.-Etim.: de fra$\mathrm{t} r$ in us, derivado de frater 'hermano' ( $D C V B)$.-Areas: Baleares; Valencia, Castellón (Colón, Voc. Cast.); Dènia (EG); Benicarló (EA); Ull-

1 Según Guarnerio, Dial. cat. Aighero, 355, y Gina Serka, Aggiunte e rettifiche algheresi all'A Atlas Lingïistic de Catalunya» di $A$. Griera (cc. I-586), "L' Italia dialettale», III, I927, p. 2 Io.

- M. L. WAGnis, La lingua sarda, p. 189.

- Véase Rollifs, ob. cit.

- Menorca esta vez se aparta de su isla vecina y va pareja con el cat. oriental (vid. Mor,I, Dial. Ciutadella, p. 438: engronxadora 'cadira apta per engrousar-s'bi)

- Ragistrado también por Cor,ón, Voe. Cast. 
decona ( $E R$ ); Lérida (EF); Oliana (especialmente los ancianos) ( $E E$ ); Alguer farri 1.-Cat. ant.: Procés de les Olives, 2194 (DCV B); F. Eiximenis, Contes y Faules, p. 54: «E per conservar sanitat ús ab fembres sovint; e per tal que no faça a negú injúria, faç-les-me cercar fadrines e trob que mills me'n sent»; J. Roig, Spill, r302.

Iìn Ibiza sólo se usa la forma masculina fadrt, reservándose atlota para el femenino.

Se trata de una concomitancia semántica, pues fadri, con el sentido de 'persona joven' es común a todo el dominio catalán. Este es el significado primario, del que ya en la época medieval se desprendió el de 'persona no casada', siguiendo un desarrollo semántico normal, que han sufrido otras palabras cuyo significado básico era el de 'joven': cat. mosso 'soltero' (Cerdeña, Benabarre); mossa "dona no maridada" ('Tremp, Lérida) ( $D C V B)$; arag. mozo 'joven de dieciséis a dieciocho años aproximadamente' y 'soltero' (Ansó) ${ }^{2}$; andaluz mozuela 'soltera'; andaluz y colombiano niño, - $a$ 'persona soltera' 3 ; inglés bachelor 'soltero' < fr. ant. bacheler 'joven' 4 .

Lil equivalente oriental, soller, sólo lo tenemos documentado en el Dicionario latino-catalán de Nebrija ${ }^{5}$, de 1560 , cn que abundan los castellanismos. Corominas, después de rechazar la ctimologia tradicional sol i t a r i m, afirma que soltero fué al principio sinónimo de 'suelto' y después se especializó en el sentido de 'no casado', con el que aparecen a veces el cast. suelto y el cat. solt ( $D C E C$, s. v. absolver). Probablemente tan castizo es fadri como solter, pero tenemos la impresión de que el primero es más genuino, pues su uso constante en los autores antiguos contrasta con las citas más tardías de solter.

I5. PADRI, -INA 'abuelo, -a'.-Cat. cen. avi, àvia.-Etim.: de p a trin a, derivado de pater.-Areas: Mallorca, gran parte del catalán occidental y las localidades de Santa Coloma de Queralt, Avinyó y Pobla de Iillet, situadas en el catalán oriental, pero a poca distancia de la frontera que separa éste del occidental ( $A L C$, mapa núm. I82). Véase mapa número 3 .

1 P. Catara I Roca, Invilació a l'Alguer actual, Palma de Mallorca, I957, p. 80 .

2 BADIA, Contrib.

- Jumio Tobón Betancourt, Colombianismos, Bogotá, 1953, 2." edición.

- Vid. Winstik's, New International Dictionary of the English Language, London, I9II, s. V.

- NubRJa, Lexicon, I 560: "Ślter o soltera no casats celebs, celebis". 
No hemos podido encontrar ningún texto antiguo en que aparezca padri significando 'abuelo'. En cambio es frecuente encontrarlo como sinónimo de 'padrino de bautismo': alo christià... pren un padrl, que vulgarment li diuen compare...". (Sinodals Vich, I59r, 7I, ap. Dicc. A guilb.) Como es costumbre extenclida en todo el dominio que los abuelos sean los padrinos del recién nacido, es decir, que el avi sea padrí y la àvia, padrina, estos últimos nombres, puramente accidentales, han pasado a significar 'abuelo, -a' en las áreas señaladas y han ido retirando paulatinamente los términos primitivos. Pero esta sustitución es relativamente reciente $y$, además, parcial, pues los dialectos de que tratamos reflejan a veces una vacilación. Según el $A L C$, algunas localidades mallorquinas en que llaman padrí al 'abuelo', poseen dvia como apelativo femenino y al revés ( $v$. mapa número 3 ). Por otra parte, en Mallorca, hasta hace poco, a los abuelos de familia rica, de buena posición, se les trataba de senyor avi y senyora dvi(a).

Este desplazamiento semántico de padri, -ina, aplicado a los abuelos aunque no scan realmente 'padrinos', ha traido consigo la adición de una perifrasis (padri o padrina de ses fonts, padrt o padrina jove) cuando se trata de designar a los que, no siendo abuelos, han sido los padrinos de un niño (Mallorca).

Esta innovación no ha llegado a Ibiza ni a Menorca En ésta, se mantiene avi con el artículo aglutinado: savi ${ }^{1}$. En Ibiza alternan avi, major y uelo (pron. wẹ́lu). Esste último, flagrante castellanismo, se extiende también, con sus variantes fonéticas, por el reino de Valencia, alternando con iaio.

I6. CEMENTERI 'cementerio'.-Cat. cen. ceninteri.-Etim.: del latín co e meteri u m .-Areas: Baleares, Rosellón, Conflent," Vallespir, Capcir, Cerdaña, Esterri, Llavorsí, Fraga, 'Tortosa, Benassal, Valencia, Alzira, Pego, Alcoy ( $D C V B$ y $A L C$, mapa núm. 457); Dènia (EG): Ulldecona (ER); Benicarló (EA) 2; Arán (ALC; Condó, Voc. aranés): Véase mapa núm. 4.-Cat. ant.: R. Llull, Blanquerna, 26: "Com veurem lo cementcri, adonchs es hora de cogitar en la mortn; Ordenacions de Valls, a. I3I7; Recull de Eximplis e Miracles, II, I8 y I, I67; Faules Isòpiques, I52 (DCVB).

Cementcri procede de coemete ri u m palabra tomada del griego

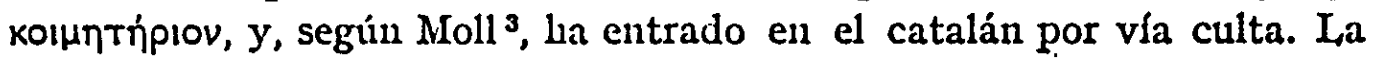

3 Mol, Dial. Ciuladella, $\$ 46$.

- Para Valencia, vénse también M. Gadisa, Dicc. Gen.

2 I. DR. B. Mor,., Gram. hist. cat,. p. 280. 


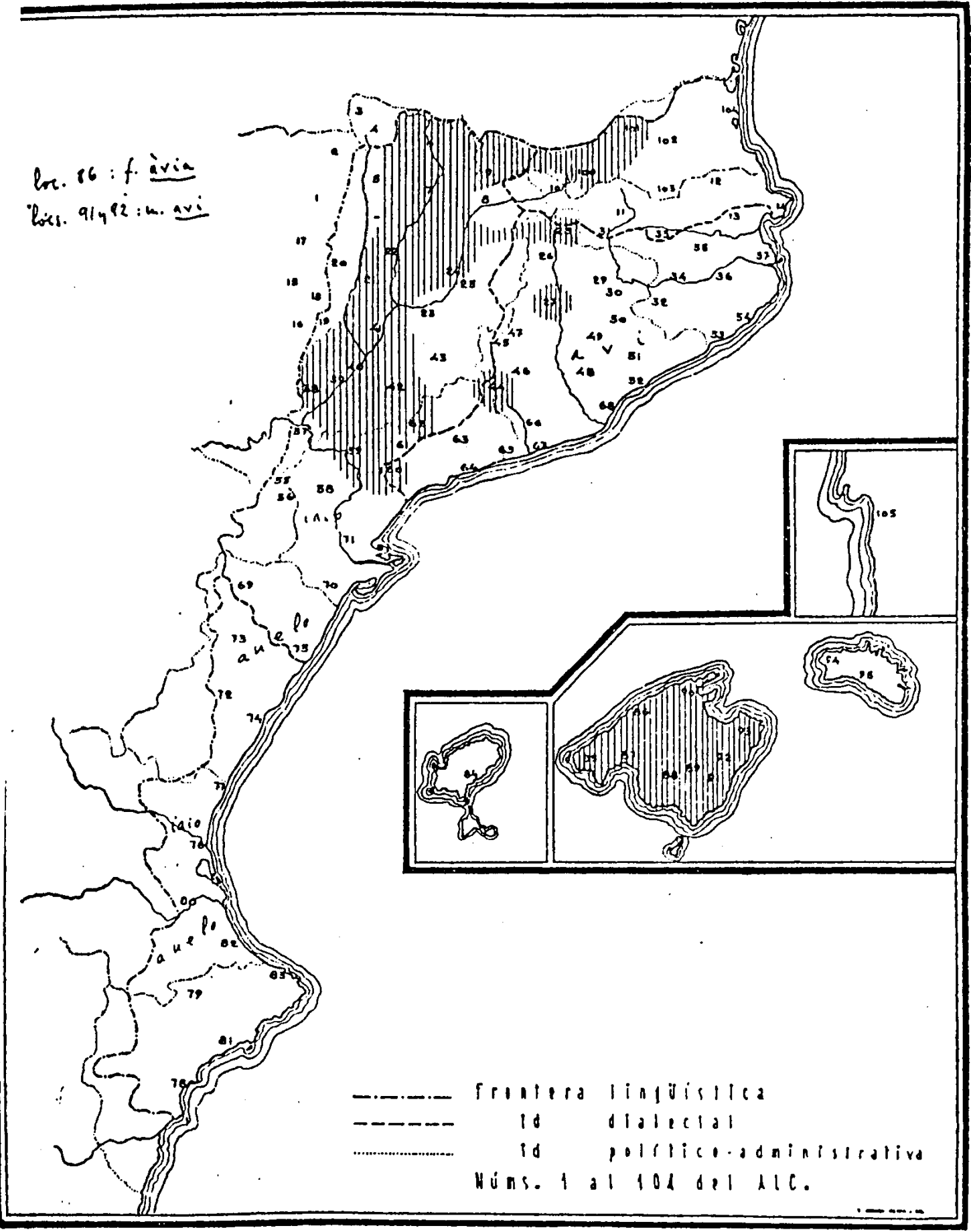

Areas de PADRI, - INA 'abuelo,-a' (seguin ALC, I82) 


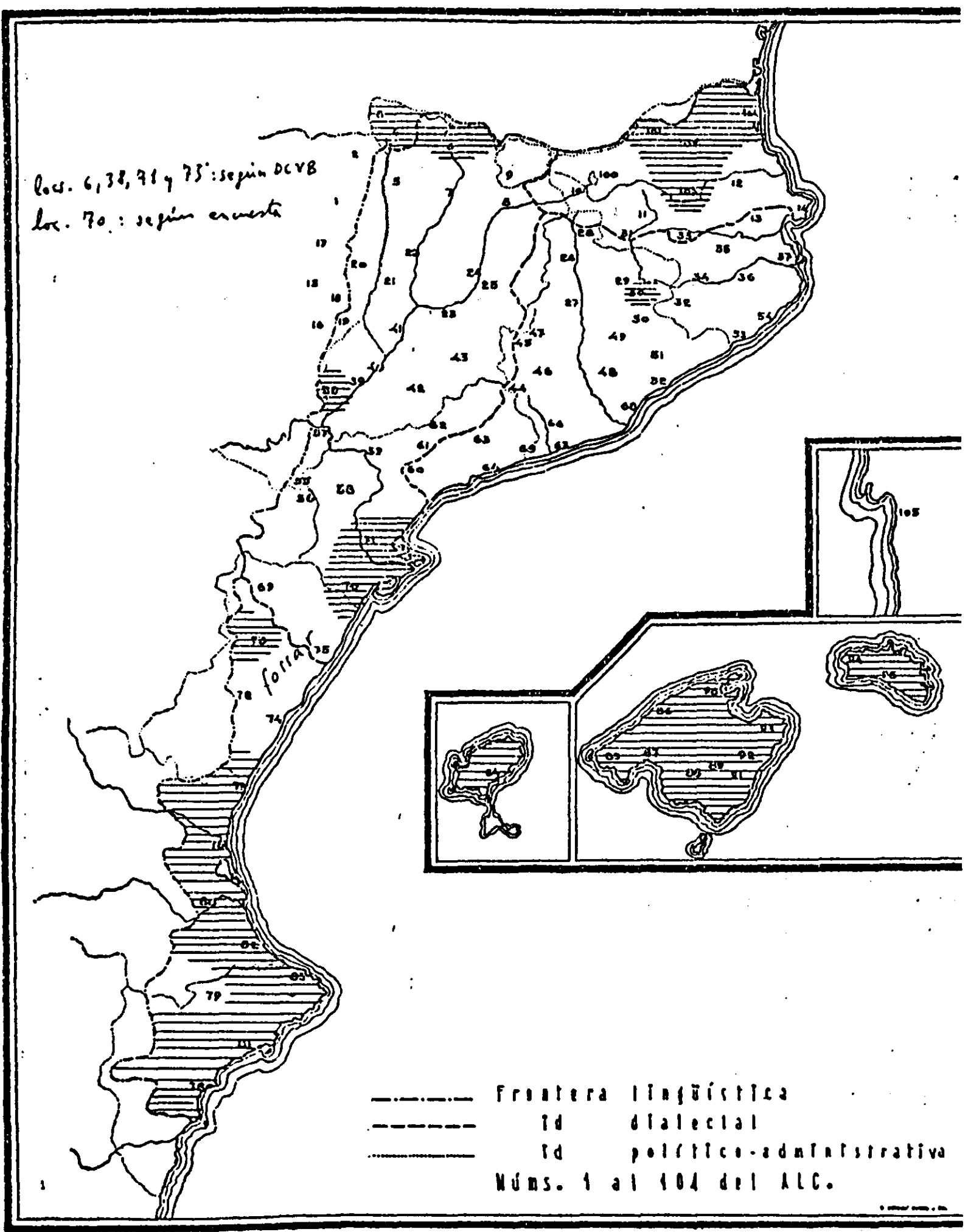

Exlensión de CEMERNTERT frente a cal. cen. CEManTIRI (según ALC, 457) 
variante cencntivi ha sufrido inflexión de la $e$ por influencia de la yod de la sílaba final ${ }^{1}$ y refleja un tratamiento más popular. Se documenta también en catalán medieval, pero los testimonios son especialmente barceloneses, un documento de I372, del Archivo Municipa lde Barcelona $(D C V B)$, y un ejemplo de un escritor barcelonés, B. Metge ${ }^{2}$.

\section{Partes del cuerpo.}

I7. BESCOLL, BA'TCOLL 'pescuezo, cogote'.-Cat. cen. clatell.-Etim.: de "p ost collum 'darrera el coll' amb el primer element modificat per influència de mots amb bis- (bescoll) i per contaminació cle batre (batcoll) i de bè (becoll)" ( $\left.D C V B^{3}\right)$.-Areas: Baleares, Igualada, Massalcoreig, Gandesa, Tortosa, Vinaròs, Morella, Castellón, Llucena, Valencia, Sueca, Xùtiva, Gandia, Alcoi, Pego, Alicante $(D C V B)^{3}$; Valderrobres (EL); Ulldecona (ER).-Cat. ant.: Llegendes rimades de la Biblia de Sevilla; Extimaciones bonorum heredilatis beali karoli (doc. s. xv); $\vec{k}$. Alcgre, Trans/ormacions Ovidi: "lierint per lo batcoll a pentalon; Guido de Cauliach, Inventari o Collectori en la part cirurgical de medicina; M. Dieş, Llibre de Menescalic; Faulles Isópiques (ap. DCV B); Nebrija, Lexicon, I560; Torra, Thesaurus, I653.

$\mathrm{Si}$ exceptuanos algunos puntos aislados, este vocablo es totalnente desconocido en las áreas orientales, donde sólo se usa corrientemente clatell. Esste también es frecuente en catalán occidental, pero en algunas zonas, como Castellón, se hace una matización en el significado de cada uno de los términos4. İn Mallorca, en cambio, no existe tal diferenciación y clotell, forma antigua de clatcll, fiel a la etimología $(<c l o t)^{5}$, es la clenominación más común, que se ha impuesto a becoll, de uso más limitado.

18. BESCOLLADA, BATCOLLADA 'cogotazo, pescozón'.-Cat. cen. clatellada.-Litim.: derivado de bescoll o batcoll (DCVB).Areas: Mallorca, Menorca (DCVB); Fraga (Barnils, Cat. Fraga); Maes-

1 Ibidem, p. 75. Como psalteriu > saltiri, sepia > sipia, etc.

2 B. Metcr, Llibre de Fortuna e Prudencia, ap. B. Metge y A. TuRMeda Oures Menors, Barcelona, I927, ENC, p. 63.

- Lil testimonio de Dènia, corroborado con nuestra encuesta $(E G)$; el de Castellon, por Corón, Voc. cast. y G. GrRONA, Voc.; el de Valencia, en general, por M. GADLA, Voc., I5.

- G. Cor,ún, Voc. casl.

- J. Corominis, Dis Aup i Pirincu, "Romanica Helvetica", XX, p. 567 , nota 2. 
trat, Llucena, Valencia, Alcoi, Pego, Alicante $(D C V B)^{1}$; Benicarló (EA); Ulldecona (ER); Dènia (EG).-Cat. ant.: B. Fenollar y P. Martínez, Lo Passi en cobles: aLos uns li donaren de grans bascollades"; La sanctissima passio (s. xvi) (DCVB); Nebrija, Lexicon, I560; Torra, Thesaurus, 1653.

En estas localidades de las áreas occidental y balear convive generalmente bescollada ${ }^{2}$ (o bal. batcollada) al lado de clatellada (o bal. clotellada), que es el único término usado en el catalán central. En Mallorca se obseva cierta decadencia de batcollada, que pierde terreno frente al sinónimo señalado. Es normal que la coexistencia de dos términos no perdure largo tiempo, si no se efectúa en uno de ellos una especialización de sentido, de modo que uno no excluya al otro (comp. bescoll y clatell en el castellonense, $\S \mathrm{I} 7$ ).

9. MORRO (más usado en plural, MORROS) 'labio, hocico' (aplicado indistintamente a personas y animales). - Cat. cen. llavi (personas), morrc (animales).-Iitim.: de una forma latina o gótica $\mathrm{m}$ u $\mathrm{r} \mathbf{\mathrm { us }}$, producida probablemente por onomatopeya (Meyer-Lübke); o de una voz prerromana, como el vasco murru, muru 'montón, morro de monte' (Diego, Dicc. Etinr.) o de la onomatopeya m u I r - del refunfuño (Corominas, $D C E C$, s. v.).-Areas: Mallorca, Menorca ( $D C V B$ ); Ibiza (Inf. M); Valencia ${ }^{3}$; Castellón (Colón, Voc. Cast.); Ulldecona (ER); Rosellón (DCEC); Bielsa morros 'labios'; (Badía, Bielsa)' y aragonés en general. Catalán ant.: Corbatxo (DCVB); J. Roig, Spill, 2536: rab unt de suja - e de rovell, - ab cert vermell - tret d'escudelles, - morros e celles - s'empeguntavay.

En catalán antiguo abunda la documentación de llavis, cuya frecuencia de uso se impone a la de morros referida a personas. Barnils ${ }^{6}$ considera morro como un fósil de la lengua y afirma que es muy posible que la lengua hablada se haya servido principalmente de él, para perder terreno después ante la presión del cultismo llavi. Quizá venga apoyada esta opinión por el hecho de usarse el castellanismo labios para las personas y morros para los animales en algunas localidades de Valencia y

1 Véanse también: para el Maestrat G. Gikons, Voc., y para el valenciano, Mr. GADEA, Voc.

- En las hablas valencianas, en general, la pronunciación es bascolld.

- P. BARNis, Fossils de la llengua, III, BDC, III, p. 35, y M. GADEA, Voc. 17.

- Téngase en cuenta también la frase del nunciuno beber a morrete "beber aplicanclo los labios al botijo o a la jarra' (G. Soriano, Voc. murciano).

- 1'. BARNits, Fossils de la llengua, III, BDC, III, p. 35. 


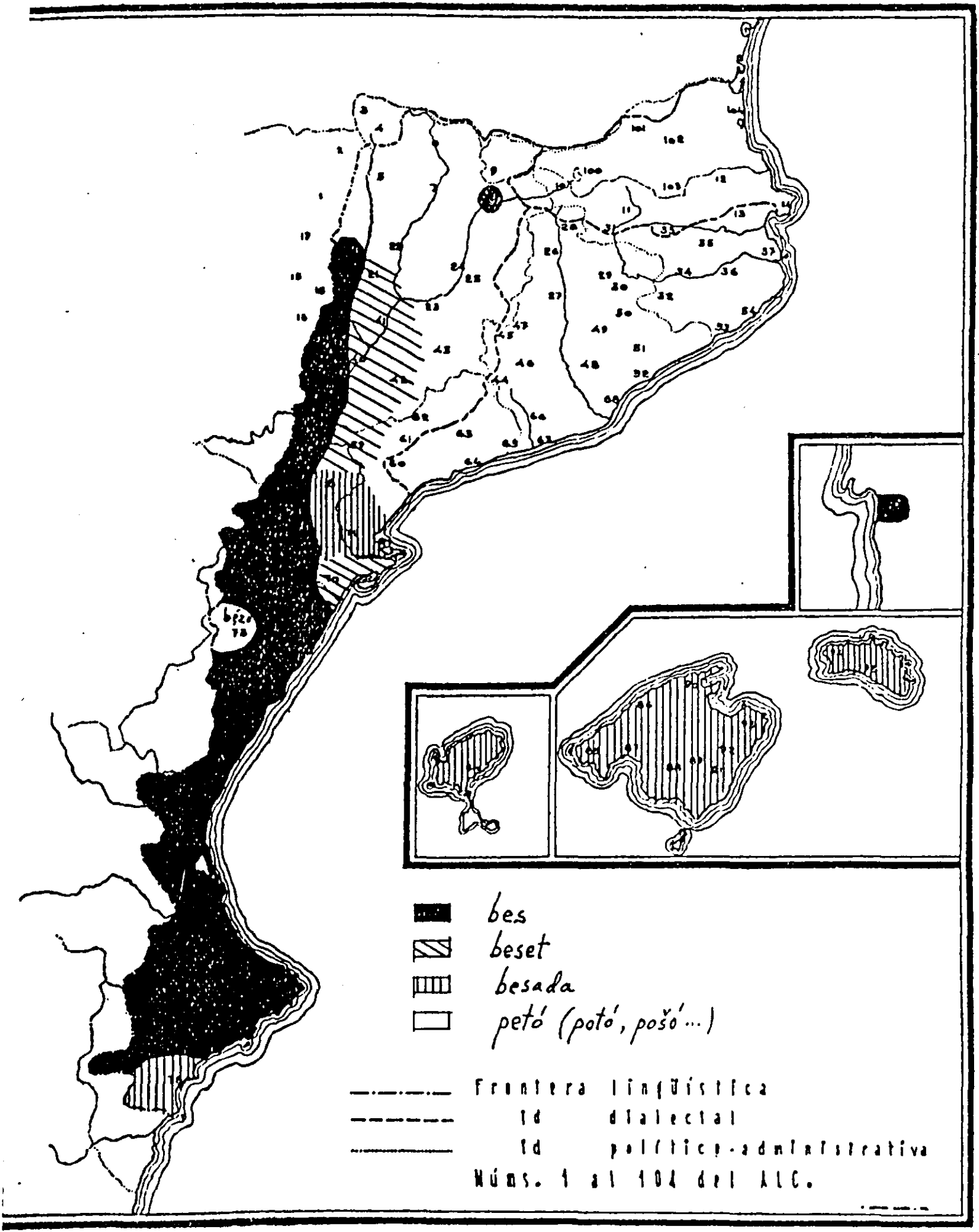

Dénominaciones de 'beso' en catalän (seguin $A L C, 263$ ) 
Alicante, citadas por el mismo Barnils, a las que podrfamos añadir Valderrobres. Es decir, que, en dichos puntos, la introducción del término castellano habria provocado en la lengua popular una restricción del campo semántico de morro, pasando a designar el 'hocico'.

Sigue la interpretación de Barnils, J. Corominas, quien considera que tanto el cat. llavi como el cast. labio son latinismos introducidos en estas lenguas en la época renacentista y que vinieron a sustituir denominaciones tradicionales, como morro, por el matiz peyorativo que habia adquirido en ciertas regiones ( $D C E C$, s. v. morro) ${ }^{1}$.

Otra explicación es también posible. Morro, quizá a través de una comparación con el significado geográfico de este vocablo, registrado en vasco (véase el comienzo de este parágrafo), se habría aplicado primero al abultamiento exagerado de la parte anterior de la cara de ciertos animales, extendiendo su área semántica a los labios de las personas, seguramente en el lenguaje familiar, a través de frases despectivas, irónicas o festivas, hasta desplazar en parte a llavi. Parecida extensión de significado es la que ha sulriclo rost r u m que, significando al principio 'pico de las aves', la llegado a aplicarse también a la cara de las personas.

De todas formas, la interpretación de Corominas parece la más aceptable, $y$, además, viene en apoyo de la conclusión general de nuestro trabajo.

20. BISADA 'beso'. - Cat. cen. petó.-Itim.: derivado de besar.Areas: Baleares, Alicante, Tortosa, Gandesa ( $A L C$, mapa núm. 263); Ulldecona ( $E R)$; Dènia (EG). (Véase mapa núm. 5).-Cat. ant.: Tirant: "E fo tan saborosa la besada...»; A. Martí Pineda, Consells a un casat (s. xvi) (DCVB).

Fin el catalán occidental, junto a las áreas señaladas donde aparece besada, se extienden otras dos con el mismo radical: casi todo el reino de Valencia y la faja más occidental del leridano poseen bes, lo mismo que Alguer; otra faja del leridano, vecina a la señalada, usa, en cambio, el diminutivo beset. Observamos aquí una oposición entre el tipo léxico bes, beset, besada, que abarca las islas, todo el valenciano y parte del leridano, frente a petó y sus múltiples variantes fonéticas ${ }^{2}$, privativo del catalán oriental, cuya frontera rebasa hacia el oeste, especialmente en la zona septentrional. Fsta forma carece de documentación en catalán antiguo, en el que encontramos besada, besar, besament, o,

1 En aranés se envileció murro, que se aplica a los aniuales, mientras que se reserva pols para las personis (ES).

3 Véase $A L C$, mapa núu. 203. 
desde la segunda mitad del siglo xvi, bes. A juzgar por la documentación medieval, petó parece que ha de ser considerado como vocablo de creación relativamente moderna, y en este sentido sería aceptable la interpretación de I'. de $B$. Moll, quien lo considera formado sobre pet 'ventosidad' $(D C V B$, s. v.). En tal caso, el origen del cambio scmántico estaria prcbablemente en torno al mundo infantil, que gusta de los "besos sonoros", y quedaría explicado el hipotético diminutivo, de carácter afectuoso, formado con el sufijo $-\delta$ (comp. infantó, diminutivo de infant, etc...).

Por otra parte, fuera del catalán, nos encontramos con los vocablos provenzales putunar y putu, que han de estar relacionados con el provenzal pot 'labio', derivado del románico $\mathrm{p}$ o $\mathrm{t} \mathrm{u}$, de origen onomatopoyético. En catalán, al lado de petó, se usa potó en el catalán occidental y en la lengua antigua se registra pot 'labio' (Moll, Supl. REW 2642 y $D C V B$ ). Ahora bien: ante esos datos, parece más verosímil un emparentanjento etimológico con pot $t u$ que un ennoblecimiento de significado a partir deJ derivado de peditu. Potó scría la forma primitiva que se habría disimilaclo cn el catalán oricntal (comp. xocolalc, a veces pronunciado šckuláte; o, mejor *gol/6 > galló pron. gẹfọ́ vid. § 67). Lil carácter popular del término nos explicaría su auscncia de los textos literarios antiguos.

Dejando aparte el problena etimológico, nos interesa destacar el hecho de que los tipos léxicos del balear y de la mayor parte del catalán uccidental aparecen documentadísimos en la Edad Media, sin que tengamos dudas sobre su antigüedad, mientras que petó y sus congéneres (potó, potxó, etc.) no tienen uingún apoyo en la lengua antigua.

2I. CLAU 'colmillo'. - Cat. cen. ullal. - Etim.: del lat. c 1 a v u m .Areas: Mallorca, Ibiza (Inf. M); Valencia (Inf. S; MI. Gadea, Voc., I6); IBetxí (Castellón) (Colón, Voc. Cast.); Maestrat (G. Girona, Voc.); U1ldecona (ER); Benicarló (EA); Falset, Montblanc, Valls ${ }^{1}$.

E1 carácter puntiagudo del colmillo ha dado origen a esta curiosa metáfora. No hemos encontrado documentación antigua.

Iin otras comarcas del catalán occidental se usa colomello, probable mozarabismo (parte de Castellón, según Colón, Voc. Cast.; Valderrobres, $E L$ ), y canina, con sus variantes fonéticas, cadina (Oliana) y caina (Borges, según Griera, art. cit.).

22. NIRVI, NYRVI 'nervio'.-Cat. cen. nervi.-Etim.: del latín n e r v i u m.-Áreas: Nirvi Baleares, nyirvi Lérida, Calaceite, Tortosa,

1 A. Griers, Allas Lingütstic de Calalunya. Inlroducció. Mapa núm. 9, $B D C$, V.I. Para el Camp de Tarragona, véase también Montoliu, Voc. 
Morella ( $D C V B)^{1}$; nirvi Oliana (los campesinos) (EE); Balaguer (la gente humilde) ( $E V)$, Ulldecona (conviviendo con nyirvi) (ER).-Cat. ant.: R. Llull, Felix de les maravelles del mon; Lo Passi es cobles: vab venẹs. e nirvis del cor divinaln; Doc. a. $\mathrm{I}_{5} 65$ ( $D C V B$ ).

Nirvi o su forma palatalizada por influjo de la $i$, nyirvi, presentan la evolución popular del latín nervi u m, con inflexión de la ĕ causada por la yod de la sulaba posterior. Frente a estas formas vulgares, en el catalán central ha arraigado el cultismo nervi, asl como en la mayor parte de Valencia, donde alterna con nyervi. La convivencia de las dos formas en ciertas zonas occidentales que señalamos al comienzo de este parágrafo, puede explicarse por razones de tipo social: la voz inflexionada es privativa de la gente campesina o menos cultivada, mientras que el cultismo se extiende al resto de población que pretende hablar más correctamente. Puede ser la supervivencia de una antigua dualidad de formas.

En las Baleares únicamente se conoce nirvi. Las hablas de estas islas nos ofrecen abundantes cjemplos de inflexión de la è: bistia, espicia, frente al catalán común bdstia, espicia ${ }^{2}$; en cambio, paradójicanıente, cementeri, sin inflexión, frente al cat. cen. cementiri (cfr. § I6).

23. CARÁC'lER 'cara, fisonomia'.-Etin.: del lat. c la a a cter 'signo gráfico' (DCVB).-Areas: Mallorca, Valencia ( $D C V B)$; Ibiza (Inf. M.); Oliana ( $E E$ ); Dènia ( $E G$ ); murciano caraite (Yecla, Villena, etcétera) (G. Soriano, Voc. Murciano); aragonés carácter ${ }^{3}$.

Se trata de una etimología popular, que pudo operarse independientemente en ambos dominios. En el vocablo caràcter, cuyo sentido actual es relativamente noderno, pues en la Edad Media tenía el de 'señal, figura, forma o marca' ", el pueblo creyó ver un derivado de cara, y de esta forma, caràcter, además de expresar las cualidades espirituales, pasó a definir también, en boca del vulgo, cualidades físicas, externas.

24. GARRI', -IDA 'garrido, hermoso'.-Etim.: del árabe ja ri , según el Diccionario de la Academia y Meyer-Lïble. (Vid. $D C V B$ ): del cast. garrido, probablemente participio de garrir < lat. gar rire

I Mestra, Voc. Tortosa, también registra nyirvi para Tortosa.

- Vid. A. BADfA, Gram. hist. cat., \$ 49, II.

- Jordana, Vocabulario aragones, ap. Academia Española, Diccionario historico de la lengua española, Madrid, I936, II.

- S. de Covarrubias, Tesoro de la lengua castellana, ed. de M. de Riquer, Barcelona, 1943. In francés significaba en la Iedad Media talisman portant un sigue magique*. (1). LERCH, Talent - Eine Wort - tund kulturgeschichtlichs Studie, "Die neueren Sprochen, Zeitsclurift für den neusprachlichen Unterricht, 4r, I933. p. 420). 
'charlar, parlotear', 'gorjear', según Corominas, DCEC.-Areas: Mallorca, Alicante, Valencia, Tortosa, Vallés ( $D C V B)^{1}$; Maestrat (G. Girona, Voc.); Ulldecona (ER).-Cat. ant.: Regles de esquivar vocables: "Livitar de dir... gay per dir garrit o gentil o polit" (ap. DCV B); Nebrija, Lexicon, I560: "garrit. elegans, elegantis; lautus, lauta, lautum".

Corominas cree que esta palabra no es genuina del catalán, sino que fué tomada "del romancero castellano por conducto de la canción popular" ( $D C E C$ ). De todos modos, la introducción de tal forma tuvo lugar en época temprana (s. $\mathrm{xv}$, por lo menos).

25. C A L C I G A R 'pisar'.-Cat. cen. trepitjar.-Etim.: de c a 1c i c a re, derivado de ca $1 \mathrm{x}$ 'talón' (según Montoliu, $B D C$, III, p. 40).Areas: Mallorca, Menorca, Alguer, Alicante, Valencia, Tortosa, Gandesa, Esterri, Rossell, Ampurdán, Gerona ( $D C V B$ ); Ibiza (caduco; Inf. M); Maestrat (G. Girona, Voc.); Arán kausigá (Condó, Voc. aranés; Corominas, Voc. aran.; BDC, VI, p. 36).-Cat. ant.: Homilies d'Organya: "Cadeg prop de la via e fo calcigad"; Desclot, Crónica; Muntaner, Crónica; l'ere IV, Crúnica; Doc. a. 1286; Dccancró (versión catalana 1429); A. Martí Pineda, Consclls y bons avisos dirigils a una noble senyora... (s. xvi) (DCVB); Vida de Sant Anlhiogo (s. xv); Riegles de esquivar vocables...: "peltrigar per calcigar».

Iil $D C V B$ observa que las regiones que cita son aquellas en que el vocablo ha sido verificado como vivo. Añade que en Menorca es de uso frecuente, mientras que en Mallorca está en declive, pues sólo se oye en boca de los ancianos o formando parte de las expresiones estereotipadas en el lenguaje especializado, como es el de los fabricantes de ollas.

En el Rosellón, Cerdaña, Gandesa y Benassal, vive una variante, paltrigar, que será debida a un cruce de calcigar con trepitjar ${ }^{2}$.

26. ESGARRONAR 'tocar con la punta del pie el zapato del que va delante, haciéndoselo salir'.-Cat. cen. eslalonar.-Etim.: formado sobre garró.-Areas: Baleares, Ampurdán, Tarragona, Pla d'Urgell, Ribera d'Ebre, Maestrat; Valencia desgarronar ( $D C V B$ ); Villar del Arzobispo (Llatas); Lérida (EF); Tortosa (Mestre, Voc. Tortosa); Valderrobres (EL); Ulldecona (ER); Benicarló ( $E A)$; Dènia (EG).

Con este sentido no poseemos documentación antigua de ninguno de estos vocablos. Estalonar sí que aparece, pero con el significado de apo-

1 Otras documentaciones: Valencia (EsCRIG; M. (inUEA, Voc., 93).

2 Véase $D C V B$. Para el rosellonés, C. Granuó, Voc. rosellonés. 
yar, sujetar algo con un palo' 1, formado sobre estalb 'puntal', términos todavía vivos en Mallorca ${ }^{2}$.

No hay una separación muy neta entre las áreas de estalonar y esgarronar. Ein Menorca, por ejemplo, parece que también se usa estalonar como sinóninuo de esgarronar.

27. ILENLGADA 'resbalón'.-Cat. cen. relliscada.-Etim.: postverbal de llenegar, derivado de 1 en icare (formado sobre len is 'suave') ( $D C V B$ ).-Areas: Baleares; Alta Ribagorza ixencgada (Ferraz, Voc. Alta Ribagorza).-Catalán ant.: Curial e Giielfa, ed. Miquel y Planas, p. 324, 1. I0979: "... e, a manera de qui llenega, ha navegat suaument e quietau. Más documentada está todavía la variante allenegar: Fenollet, La Historia de Alexandre; A. Canals, Scipió i Anibal; Genebrada, Libre de Consolació de Philosophia (DCV.B); Tirant.

En balear no sólo es frecuente el sustantivo sino también el verbo llenegar, no usándose las formas continentales relliscar, rellissar o esvarar. La variante esllencgar aparece en catalán oriental con el significado de "estirar, allargar un cosa fent-la cedir per elasticitat (Ampurdán, Plana de Vic, Barcelona) ( $D C V B$ ) o con el de 'desmoronar' (cfr. Calaf esllenegada 'desmoronamiento', ALC, mapa núm. 749, L'esllavissada). Hay, pues, una pequeña diferencia de matiz. Además, en algunas regiones orientales (Vallés) y también occidentales (Bellpuig), hay una seta de la especie "Hygrophorus limacinus", que, por tener la superficie húmeda y viscosa se llama llenega, postverbal de llenegar (DCVB).

\section{Indumentaria.}

28. CAPELL, 'sombrero'. - Cat. cen. berret, sombrero. - Etim.: ca p pe 11 u (DCVB).-Areas: Baleares, Sopeira (Oliva, Cat. Sopeira, p. 42I).-Cat. ant.: Doc. año II8I; R. Llull, Libre de Contemplacio; Jaume I, Crònica; Desclot, Crònica; Tirant, c. 62: "Tornaren altra volta a levarse los capellsw; B. Metge, Somni ( $D C V B$ ).

Como vemos, capell ha desaparecido de casi todo el dominio del catalán continental como término usual, sinónimo de sombrero. No obstante, continúa siendo usado con valor traslaticio, tanto en las áreas occiden-

I Desclor, Cronica, ed. ENC, II, p. I 16: «Mas aprés d'assd, ne feeren altra que and̀ tro a la barbacana, e puys estalonaren-la e feeren-lui foc.....

- Para una interpretación homonlmica de estalonar 'apuntalar' y como sino. nimo de esgarronar, véase $A$. GRIIRA, Éludes de Gégraphie Linguistique; Anuari de l'Oficina Romanica de Lingüistica i Literaturan, V, 1932, p. 77. 
tales, donde capell puede aplicarse al capullo que fabrica el gusano de seda $^{1}$ (comp. arag. capel con este mismo sentido ${ }^{2}$ ) o a la faja de nubes que se ponen en la cima de una montaña ${ }^{3}$, como en las orientales, donde puede referirse al haz que se pone encina del tresnal, en forma de paraguas, para impedir que pase el agua de la lluvia ${ }^{4}$ al caballete del tejado - bien, en el lenguaje especializado de la industria del corcho el utros de canemàs que s'afegeix a la boca de les saques o balots de taps, quan per ésser massa plenes és impossible cosir-les" ${ }^{6}$, etc., etc.

Sombrero y berrct vinieron a hacer la competencia al vocablo genuinamente catalán capell. El primero es un castellanismo claro, cuya introducción data de época antigua, pues en el siglo xv ya se condena la pronunciación sembrero por sombrero ${ }^{\circ}$ y Nebrija ya cita esta forma al lado de capell ${ }^{7}$. Asi, pues, debió de arraigar muy pronto e incluso se extendió a Alguer ${ }^{8}$ y al sardo logudorés y campidanés ${ }^{\circ}$.

Berret, en cambio, vocablo típicamente catalán, sufrió un desplazamiento de significado, pasando de 'gorro, birrete' a 'sombrero'. La significación primitiva que poscía el catalán medieval se ha mantenido en balear, al no desaparecer capell, con lo cual la lengua no tuvo necesidad de forzar berret a un corrimiento semántico.

La introducción de palabras extranjeras afecta de un modo especial a las que se reficren a la indumentaria y al vestido, que cambia con los tiempos y cuyas modas se adoptan en los países vecinos junto con los nombres que las definen. Ya tendremos ocasión de estudiar en este mismo capitulo la influencia castellana en la denominación de algunas prendas de vestir, particularmente efectiva en la zona oriental.

29. CALCES 'medias'.-Cat. cen. mitges. - Etim.: del lat. c a $1 \mathrm{c}$ e a $(D C V B, D C E C)$.-Areas: Mallorca, Menorca, Alguer, Fraga, Gandesa,

1 Tarragona, Tortosa, Valencia y Alicante, según $D C V B$.

- Según Borao, Dicc. y Pardo, Dicc.

- lispecialmente en refranes que predicen el tiempo: "Quan Montsià fa capell. guarda't d'elln, etc. (DCVB).

- Ripollés, Plana de Vic, Llusanìs ( $D C V B)$.

- Sant Feliu de Gulxols (BDC, XIII, 1925).

- A. Badfa, Regles de esquivar vocables, núm. 298.

$?$ NenRiJa, Lexicon, 1560.

- sumbreru (MOROSI, Dial. cal. Alghero, p. 326); GuARnerio, Dial. cat. Alghero, número 356 .

- sumbrdri. A Cagliari, in tono di scherzo (WAGNer, La lingua sarda, p. 209). 
Tortosa, Maestrat, Valencia, Alicante $(D C V B)^{1}$; Ibiza (Inf. M); CasteIlón (Colón, Voc. Cast.); Denia (EG); Ulldecona (ER); Benicarló (EA); Valderrobres (EL); Enguera (Martínez). - Cat. ant.: doc. Urgel año ro55; R. Ilull, Felix; Pere IV, Cronica; Ordinacions palatines; B. Metge, Somni ( $D C V B$ ); Desclot, Crònica, III, ed., ENC, p. 63: 4... e en las cames les calses ben estretes de cuyro..." (equivale aquil a 'polainas'); A. Canals, Scipió e Antbal, ed. ENC, p. 34: a... semblants a les calçes dels minyons...n; J. Roig, Spill, v. 2I7I, 2388.

Nos encontramos ante una oposición meramente semántica. Las calces equivalían, en catalán antiguo, a "pessa de vestit que cobria el peu i la cama, ajustant-se al contorn d'aquesta" ( $D C V B$ ). Esta acepción es la que ha conservado el balear en general, junto con las áreas valenciana y tortosina, para designar las medias modernas que llevan las mujeres o también los niños. Este sentido primigenio se conserva también en el Alto Aragón (Ansó) y en el asturiano calza "calceta que sólo cubre la pierna, asegurándose al pie con una travilla" ( $D C E C$ ), o bien en derivados tales como calcilla usado en Cardós y Vall Fierrera por las generaciones ancianas como sinónimo de 'media' o 'calcetín' an Bot y Prat de Comte ${ }^{3}$, en Calaceite, Tremp, Urgel y Camp de Tarragona 4, en la Litcra ${ }^{6}$ y en Bielsa ${ }^{\circ}$, con el significado de media sin pie para uso de hombres, o bien la variante del dialecto panocho carcela $^{7}$ o calceta $^{8}$ con caracteres análogos.

Yor otra parte, en otras lenguas y dialectos ha subsistido el equivalente de calces con el valor de 'medias': calze en italiano y chausses en una gran parte de las hablas galorrománicas (Bloch-Wartburg, Dicl. Etymin.).

Al cambiar la moda con los tiempos, las calces fueron usándose más

1 Para algunas de estas localidades, la información viene corroborada con las noticias recogidas en monografías: Alguer (MOROSI, Dial. cal. Alghero, 4I), Fraga (Barnirs, Cat. Fraga), Tortosa (Mustre, Cat. Tortosa), Gandesa (J. AnaDES, Termes Gandesa). Para el valenciano, en general, véase M. GADEA, Voc., 20, y para el Maestrat, G. GrRoNA, Voc.

2 Las generaciones jóvenes prefieren milja y mitjó, términos del catalán COunín (J. CoROMINis, Cardós).

- J. Amadis, Termes... Gandesa.

- $D C V B$.

- B. Cold y Alimads, Colección de voces usadas en La Litera, Zaragoza, 1908.

- A. Badfa, Bielsa.

- Jifrónimo Ramfrez Xarré, El panocho (Vocabulario popular murciano $y$ otros apuntes de interts), Mfurcia, I927.

- G. Soriano, Voc. murciano. También ha pasado a significar tembuchado en tripa gruesa por el estilo de la butifarran (ibid.). 
largas hasta llegar a la cintura. No obstante continuó aplicándosele el mismo nombre. Cuando en el siglo XVI se separan en dos piezas, la de arriba continuó llamándose calces (comp. esp. calzas, fr. chausses) o calfons (comp. cast. calzón) ${ }^{1}$ y la de abajo, abarcando las piernas y los pies, mitges calces, que en catalán del Principado se abrevió en milges, como en castellano medias calzas se redujo a medias o en francés bas-dechausses se abrevió en bas ${ }^{2}$. Nuestras áreas se han mantenido fieles a la significación antigua $\mathrm{y}$ aún hoy las calces designan las medias, al mismo tiempo que el uso de calfons, al principio - hacia el siglo XV o XVIaplicada a la prenda que cubria el abdomen y parte del muslo, subsistió como término común para designar el pantalón moderno, impidiendo, especialmente en las áreas baleáricas, la incorporación del galicismo pantalons. ${ }^{8}$.

30. CAICETINS 'calcetines'-Cat. cen. mitjons.-Etim.: derivado de calça 'media', quizá adaptación del cast. calcetín.-Areas: Baleares; calsotins Irraga, Valencia $(D C V B)^{4}$; calcetins, Valencia (M. Gadea, Voc.); Dènia (EG); Benicarló (EA); Benabarre (Badia, Contrib.) ${ }^{5}$, Bisaurri (Haensch, p. I85).

'Tanto mitjó como calcelt parecen derivados recientes (de mitja el primero y de calça el segundo), explicables por corresponder a prendas de moderna aparición. Calceli será un término castellano, pero es curioso que ocupe con preferencia las zonas donde a las medias se las denomina calces, mientras que mitjons vive especialmente en aquellas en que se las llama mitges.

3I. C A I C O N S 'pantalones'.-Cat. cen. pantalons.-Etim.: derivado de calça. - Areas: Mallorca, Menorca, Alguer, Alicante, Valencia,

1 Todavia hoy se da este nombre a los pantalones de hombre antiguos que llegan sólo hasta la rodilla, en Sort, Bonansa, Senterada, Pobla de Segur y Pradell. mientras que en otras comarcas las llaman calca curta ( $D C V B$ ). En catalán oriental calces ha sufrido una restricción de significado al aplicarse especialmente a los pantalones de la mujer.

- Para esta evolución histórico-lingülstica, nos hemos basado en K. JAUERG, "Wörter und Sachenn, IX, 137-172; Br,OCI ET WARTBURG, Dicl. Etym. R. MUQUEL, Y PLanas, ed. del Spill de J. ROIG, II, nota a los versos 217I-2I72; DCEC.

- Sobre las vicisitudes sufriclas por esta palabra, véase: MigLIORINI, Dal nome proprio al nome comune, Genève, 1927, p. 103 y, resumido, en S. Ul, LIANN, Précis de Simantique Franfaise, Berne, 1952, pp. 244-245.

- Para Fraga, también Barnirs, Cal. Fraga.

- In Benabarre también se usa miljons. 
Tortosa $(D C V B)^{1}$; Ibiza (Inf. $\left.M\right)$.-Cat. ant.: Doc. s. xv; Docs. años I529 y r667.-Véase calces, $\S 30$.

Este término tiene particular vitalidad en las Baleares, mientras que en las localidades que cita el $D C V B$, por las noticias que hemos podido. recoger, ya está suplantado por el moderno pantalons.

La adopción del equivalente castellano calzones como vocablo para designar el pantalón moderno tuvo lugar paralelamente en el panocho ${ }^{2}$ y en el judeo-español, dialecto que, junto a calsón, usa también pantalón y la palabra turca salvár ${ }^{3}$.

No desconocemos que en el catalán oriental, así como en algunos valles de los Pirineos occidentales, los pastores se cubren las piernas con calcons, es decir, con unas antiparas de cuero que van de la rodilla al tobillo y se sujetan a un lado con botones o hebillas ( $D C V B$ ). Pero insistimos en que se trata de una oposición semántica entre nuestras. áreas y la oriental.

Pantalons es de procedencia francesa - aunque formado sobre un apelativo italiano- $y$ en Francia aparece con el sentido moderno en I65I. De allí pasa a Italia y a İspaña. Is, por tanto, voz moderna.

32. FALDETES 'faldas'.-Cat. cen. faldilles.-Etim.: derivado de falda (DCV B).--Areas: Mallorca, Ribagorza, Lérida, Pla d'Urgell, Camp de Tarragona, Calaceite, Priorat, Gandesa, Tortosa, Maestrat, Castellón, Valencia ( $D C V B$; ALC, mapa núm. $\left.795^{4}\right)$; Ulldecona (ER); Benicarló (EA); Borges Blanques (Arques, Variants... Borges, p. 39), Valderrobres (EL); Penarroja (Haeusch, p. I85). Véase mapa núm. 6.-Cat. ant.: Tirant; Trobes Verge Maria: "De caritat eren vostres faldetes" (DCVB); J. Roig, Spill, 2083 (DCV B).

Los testimonios más antiguos son de faldeles, aunque los tres son de autores valencianos. Faldilles no se documenta hasta principios del siglo xvr y es considerado como probable castellanismo por Coruminas ( $D C E C$, s. v. falda), mientras Moll lo da como seguro, por el sufijo. $-i l l a$, que tiene todo el aspecto de una procedencia castellana $(D C V B)^{5}$.

2 El vocablo es también registrado para Tortosa por MEsTrE, Cat. Tortosa.

- Calzones 'pantalones, calzoncillos' (J. RAMfrez XARRIA, El Panocho):

- MI. L. IVAGNER, Espigueo judeo-español, RFE, XXXIV, 1950, s. v. braga.

- Ademís, las faldetas lia sido registrado en Bisaurri, Renanué y Ispés (Alta Ribagorza) por Harnscir, p. 185.

- Prueba de la conciencia de forasterisuo que se tiene de este suifijo, es la reacción purista que se efectuó en Barcelona al entrar el vocablo bombilla, reacción que acabó por imponer unạ forma considerada wás catalana, bombeta. '.. 


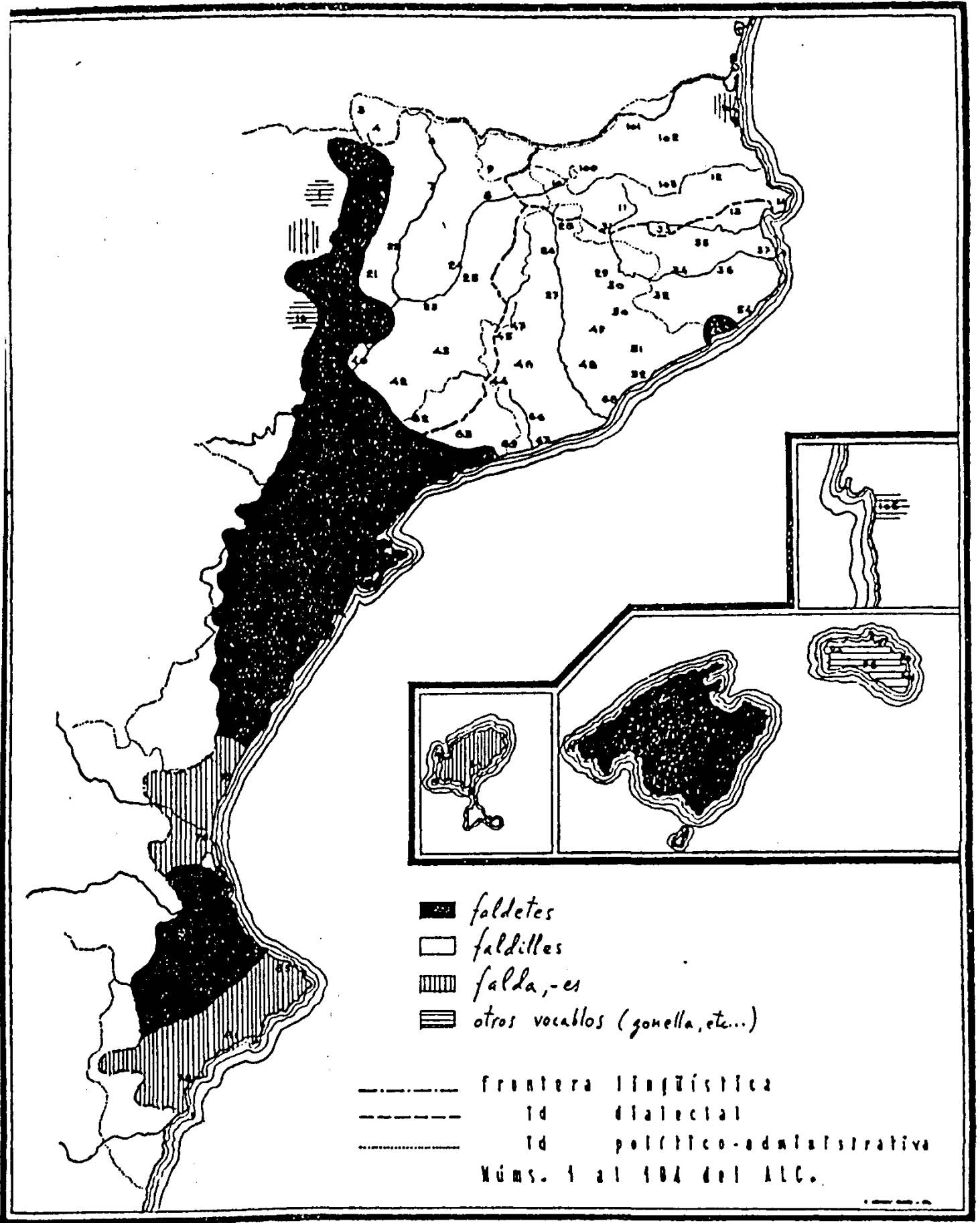

Extensión de RALDETis (seguin $A L C, 795$ ) 
Ya hemos indicado, al principio de este capítulo, con qué intensidad se notaban los préstamos extranjeros en los grupos de vocablos referentes a piezas de vestir.

\section{Vida fisiologica y sensible.}

33. BECADA 'cabezada, dormida'.-Cat. cen. becaina.-Etim.: derivado de bec, vocablo de origen céltico ( $D C V B$ ). - Areas: Mallorca; Valencia (Escrig; M. Gadea, Voc.; $D C V B$ ); Dènia (EG); Castellón (Colón, Voc. Cast.); Maestrat (G. Girona, Voc.); Benicarló (EA); Villar del Arzobispo (Llatas); Tortosa (Mestre, Voc. Tort.); Camp de Tarragona (Montoliu, Voc.).

En catalán antiguo sólo está documentada la forma verbal, general en todo el dominio con el significado de dormitar, dar cabezadas a causa del sueño: "Eills s'adormiren-llurs ajudants-vent los becan (J. Roig, Spill, r5449).

Is un ejemplo de oposición de sufijos, pero los dos tipos no ofrecen una distribución lomogénea, pues becaina se extiende también en varias zonas del dominio occidental (vid. $D C V B$ ).

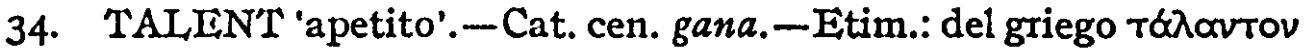
'balanza' (según Diez, Littré, Rheinfelder); derivación del sentido de 'disposición natural' salido de la parábola de los talentos (según Bloch, Lerch) ${ }^{1}$.- Areas: Mallorca, Menorca, Barbarà, Camp de Tarragona, Pla d'Urgell, Pallars, Ribagorza, Besalú, Massalcoreig, Agullana (Rosellón) ${ }^{2}$, Llofriu ${ }^{3}$ (DCVB) ${ }^{4}$-C Cat. ant.: Alcoatt. Libre de la figura del

1 Para ver resumidas las teorias dadas por los lingüistas sobre la etimologia de este vocablo, véase $J$. VENY $C, A R$, Los supervivientes románicos do $t$ a 1 e $n$ t $u$ m 'deseo', RLiR, XXI, núuss. 8I-82, 1957, \$\$ 4 У 5.

2 Iil Dicc. Aguilo da como zonas en que se usa talent en dicha acepción: Provincia de Lérida, Rosellón, Mallorca.

- Sólo las generaciones ancianas.

- Infornación que recogimos de las fichas de iLa Calaixerai gracias a la amabilidad del señor Moll.

En Mallorca talent es un vocablo de plena vitalidad, como observábamos en nuestro trabajo antes citado. Permitasenos añadir algunos ejemplos en que la palabra forma parte de un dicho popular:

-Badai no ment: o son o talent o mal d'enamorament;; o de cancioures folklóricas:

Es qui té casa a plaça està bé si té dobbers; si no en té, es a s'enrevés, perque sent s'olor des peix i sa talent no s'espassa.
Perendenga, perendenga, ja t'lo pories pensar: qui té puput en sa feina com tê talent no té pa.

(Canciones recogidas en Illucmajor.) 
uyl (s. XIv); R. Muntaner, Crónica; Enquesta del Sant Graal; Libre de les Medicines; Procés de les Olives (DCVB); F. Eiximenis, Doctrina Compendiosa, ed. ENC, p. 47: "Car sdevé's que has major talent e major set unes vegades que altres".

Talent tenfa en catalán medieval el significado de 'deseo, inclinación, gusto', que ya entonces se usó concretado en el de 'apetito, gana de comer', según puede verse en el ejemplo arriba citado de Eiximenis. Hacia el siglo xVI-Xvir irrumpe en la Romania una nueva acepción de la voz, nacida probablemente en Francia, en torno al círculo de traductores y estudiosos de la Biblia. La nueva significación de 'capacidad, aptitud, genio', se habría formado seguramente por una aplicación metafórica del talento de la parábola evangélica, entendido, por vía traslaticia, como don, gracia o cualidad concedido por Dios a los hombres. El moderno vocablo pasó al catalán, a la lengua culta, si no directamente del francés, a través del castellano. Poco a poco fué invadiendo el terreno de la lengua popular, especialmente en el catalán central, más ligado a una lengua literaria y más abierto a las nuevas corrientes lingüísticas, lo cual debió contribuir a que el viejo término talent 'apetito' entrara en decadencia y fuera desplazado en una gran parte de Cataluña. La eliminación del vocablo no era de consecuencias graves para la lengua, toda vez que dejaba otros sinónimos (gana, fam y tantos otros nombres pintorescos) que llenaban aquel hueco. En cambio, en las Baleares y algunas zonas del catalán occidental propiamente dicho, asl como del Rosellón, por ocupar áreas aisladas o laterales, por estar desligadas de la lengua culta y ser reacias a los términos de carácter abstracto, han mantenido más tiempo y con más firmeza el antiguo vocablo. Por lo que al resto de la Romania se refiere ha ocurrido algo parecido en provenzal y retorrománico ${ }^{1}$.

35. FREDOLEC, -EGA 'friolento'.-Cat. cen. fredolic.-Etim.: derivado del latín $\mathrm{frigidulu}$, diminutivo de $\mathrm{frigidum}$, con el sufijo -ec ( $D C V B)$.- Areas: Baleares, Gandesa ( $D C V B$ ).

Como vemos, fredolec tiene escasa extensión en el dominio peninsular, donde se prefiere este vocablo con otros sufijos: fredolic (cat. central y occidental), fredeluc (rosellonés). Algunas hablas occidentales y valencianas sobre fredolic han formado fredoli, como en varios pueblos de $\mathrm{Ma}$ Llorca fredolec ha pasado, por cambio de sufijo, a fredoler frẹdọlẹ́,-ẹ́rẹ (pron.

1 Hemos resunido algunos aspectos de nuestro trabajo antes mencionado, al que renitimos para ver el problema estudiado no sólo en catalán sino en las lenguns románicas. Con ello hemos anticipado alguras de las conclusiones de nuestro trabajo. 
V. Vida psicologica.

36. BECAR 'colarse, distraerse',-Cat. cen. badar. - Itim.: vid. §33. Areas: Mallorca, Valencia ( $D C V B)$, Benicarló (EA); Villar del Arzobispo (Llatas).

Se trata de una simple evolución de significado, a partir de becar en su sentido de 'dormitar', la cual no ofrece ninguna dificultad. Con idéntico significado se formó el postverbal becada.

37. BECADA 'coladura, error'-Cat. cen. badada. -Etim.: derivado de becar (vid. $\S 36)$.-Areas: Mallorca, Valencia (DCVB), ${ }^{1}$ Ibiza (Inf. M); Benicarló (EA); Villar del Arzobispo (Llatas). Véase el $\S 33$ y el $\S 36$.

38. FELLO 'irritado, enfadado'-Cat. cen. enfadal.-Litim.: probablemente del fráncico * fillo, -o n $\mathrm{s}$ 'verdugo' (DCEC).-Areas: Mallorca; Ibiza (Inf. M) ${ }^{2}$; I'cuarroja (Bajo Aragón) (I'allares, Voc. Penarroja).-Cat. ant.: Jaume I, Cronica; R. Ilull, Libre de Conlemplacio; Desclot, Cronica; A. March, LXXXVIII; Tirant; Alegre, Transformacions d'Ovidi ( $D C V B)$; B. Metge, Sermó, ed. ENC, p. 50: "Quan la veurets tornar, si plora - ni és fellona, - abraçats-la, que a poca estonafarets la pauy; J. Roig, Spill, 678r; Torra, Thesaurus, I653.

En catalán antiguo no sólo es abundante el sustantivo, sino también sus derivados fellonia 'indignación' y enfellonir-se 'irritarse', que han desaparecido de la lengua actual. Fello, en cambio, se mantiene con cierta lozania en el balear y en la mencionada localidad aragonesa, donde debe de ser un catalanismo antiguo. Pero téngase en cuenta que en Mallorca se conoce también el término que hemos señalado para el catalán central, enfadat, más corriente que felló y que se impone en todo el dominio, excepto en algunos dialectos, como el castellonense, donde sobrevive como término popular enutjar-se ${ }^{3}$, de rancio catalanismo y, por eso, incorporado a la lengua literaria.

La honda decadencia que sufrió el cultivo de las letras catalanas a partir del siglo xvi provocó el desmoronamiento y descomposición de la lengua literaria. Sólo en el siglo xIx, al calor del Romanticismo, tendrá lugar el resurgimiento de dicha literatura, que habla languidecido duraute tres siglos. Los escritores de la "Renaixença" se esfuerzan por reha-

1 Para Valencia también resgistra la voz Escrug.

- Con el matiz de 'triste'.

- Cor,on, Voc. Cast. 
cer y revitalizar la lengua literaria catalana. Por elle, acuden a lon grandes uodelos mədievales para restaurar el léxlco castizo y limpiar la lengua de las impurezas y barbarismos que se habla apropiado. Edtre las palabras reintroducidas figura fcllo, pero que sufrió la contaminación semántica del castellano felón 'traidor, cobarde' 1.

39. PUDEN'T, -A 'quisquilloso, malhumorado'.-Etim.: del latín p u t e $\mathrm{n}$ t e, en sentido figurado.-Areas: Mallorca, Valencia, Alicante, Pego ( $D C V B$ ); Ibiza (Inf. M.).

Il paralelismo estriba en una acepción secundaria, pues en la primaria de 'fétido, que despide mal olor', la voz es común a todo el dominio.

40. FLASTOMAR 'blasfemar'.-Cat. cen. renegar.-Eitin.: del latín b 1 a s t i m a e, influído por la $f(p h)$ de blas p he ma re ( $D C V B)$. Areas: Baleares, Alguer, Penedès $(D C V B)^{2}$.-Cat. ant.: J. Roig, Spill, 9528: "Veureu cridar e flaslomarn; Libre de la Mostasaferia; Lo somni de Johan Johan; Boades, Llibre dels feyts d'armes (DCVB) ${ }^{3}$.

İ̀n catalán central flastomar se considera de la lengua culta, mientras que en las áreas citadas es popularísino. En Mallorca incluso se usa el postverbal flaslomia 'blasfemia' (cat. cen. renec).

4I. MODORRO, -A 'callado, taciturno'.- Etim.: del romance arcaico * muturru, voz emparentada con el vasco mutur y que puede ser de origen prerromano o tomada del vasco, donde a su vez podría ser de procedencia latina ( $D C E C$ ).-Areas: Mallorca, Tortosa, Maestrat $(D C V B)^{5}$; Castellón (Colón, Voc. Cast.), Benassal (C. Salvador, Voc.).-Cat. ant.: L1. Requesens (Canconer Universitari, s. Xv): "Xpist procura los mudorros". Con el sentido de ignorante, falto de inteligencia o juicio claro' en: B. Metge, Sommi; Corbatxo; J. IRoig, Spill, 8733 (DCVB).

Este significado es una derivación semántica, fácilmente comprensible, de modorro, $-a$ aplicado a las ovejas o cabras que sufren modorra, enfermedad que las deja aturdidas. El sentido primigenio es particular-

1 Véase $D C V B$.

2 Para el alguerćs, también registra la palabra Morosr, Dial. Cal. Alghero.

- En los tres últimos aparece con el sentido de 'maldecir'.

- Inclulmos una zona, el Penciés, que pertenece al catalín oriental.

- Para 'Tortosa, veáse tambiéll Mistri;, Voc. Tortosa. 
mente vivo en las mismas áreas. Enn ellas, excepto en el dominio insular, se ha formado incluso un derivado verbal, anodorrar-se stenir modorra o ensopinent».

42. MAGENCAR. Iñn la expresión: no sabcr qud us magenca, cast. no saber lo que se pesca.-litim.: de magenc, formado sobre maig, por referirse en su acepción primaria a las operaciones agrícolas que se hacen hacia el mes de mayo ( $D C V B)$.-Areas: Mallorca, Menorca, Valencia (DCVB); (M. Gadea, Dicc. Gen.).

Is un paralelismo especial de nuestras dos áreas sólo en cuanto al uso traslaticio del vocablo, que, en su sentido originario de 'desortijar, aparar', es común a todo el catalán.

\section{Vida religiosa.}

43. MISSAR 'celcbrar'.-Cat. cen. dir missa.-Etim.: derivado de missa. - Arcis: Ibizal, 'I'ortosa (DCVB).-Cat. ant.: J. IRoig, Spill: "Capellans... qui tots matius missant combreguen" (DCVB).

44. DI:SENA (DIL, ROSARI) 'decenario'.-Cat. cen. dena. - Iitim.: del lat. vulgar de c ēn a $(D C V B)$.- Areas: Baleares, La Junquera, Cadaqués, Torroella de Montgrí, Banyoles, Llanàs, Olot, Mequinenza (ALC, mapa núm. 6I6); Benicarló (EA).

Es curiosa la conservación de la $-s$ - sonora intervocálica, que por regla general desaparece ( 1 lace re $>$ plaer) ${ }^{1}$. Obedecerá a cultismo, por ser palabra eclesiástica (Comp. $\S$ I6 cementeri).

\section{Enfermedades y defectos fisicos.}

45. DOLENT 'enfermo'.-Cat. cen. malalt.-Etim.: de do 1 e n t e 'que tiene dolor' $(D C V B)$.-Areas: Ibiza, 'Tortosa, Vinaròs, CasteUlón ( $D C V B$ ); Valencia (M. Gadea, Dicc. Gen.); Benicarló (EA); Ulldecona (ER); Valderrobres (EL). Comp. Bielsa dolent, - $a$ 'endeble, débil, de poca resistencia' (Badía, Bielsa).-Cat. ant.: Tresor de pobres (versión catalana del s. xrv); Doc. año I506: "Les egues son arribades assí molt flaques e dolentesn; doc. año I533 (DCVB).

De las Baleares, sólo la isla de Ibiza mantiene esta acepción. Eu Ma-

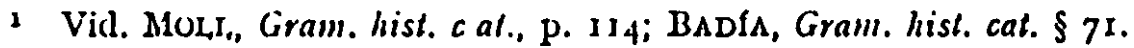


llorca debió usarse también, a juzgar por una canción popular - que reproduce el $D C V B$ - en la que aparece dolent en este sentido.

Es curioso observar cómo se lia resuelto la homonimia de dolent 'enfermo' con dolent 'malo, perverso', si es que llegó a tener lugar. Las hablas arriba scĩaladns que usan dolent en su sentido de 'enfermo', disponen de un término diferente para expresar la maldad moral: el ibicenco se sirve de mal, - a y las hablas del Bajo Ebro, Ulldecona y Valderrobres, de roin. documentado desde el siglo $\mathrm{xv}^{1}$.

46. BUA 'daño, pupa' (lenguaje infantil).-Cat. cen. pupa.-E,timologia: Voz onomatopéyica del lenguaje infantil.-Areas: Menorca, Ibiza, Maestrat $(D C V B)^{2}$; Benicarló (EA); Ulldecona (ER); Murcia, hacerse bra o buba (G. Soriano, Voc. murciano).

Simple creación onomatopéyica, típica del lenguaje de los niños. En Mallorca se dice oi-oi.

47. BURANYA, BUANYA 'úlcera, búa, pústula'-A Areas: buranya Mallorca, Menorca (DCVB); buanya Iortosa, Valencia (DCVB; M. Gaden, Voc. 46); buaña y bubaña 'llaga o puistula' Murcia (G. Soriano, Voc. murciano).-Cat. ant.: busanya: Flos de les Medicines (s. XV): "A les busanyes que es fan dins lo nas"; Llibre de Menescalia; buanya: R. Llull, Blanquerna; doc. año 1377 ( $D C V B)$.

Se desconoce la etimología de buranya, que quizá pertenezca a la familia del aranés büra 'chichón' y del cat. burrot 'tumor' (Sant Llorenç dels Morunys) ${ }^{3}$. En cuanto a buanya, Alcover y Moll lo relacionan con bua. Dada la gran afinidad fonética de esos vocablos y puesto que en catalán antiguo encontramos busanya, que pudo dar buanya por caída de la -s-intervocálica, es probable que se trate de variantes de una misma palabra 4

48. PIGOTA 'viruela'.-Cat. cent. verola.-Etim.: derivado de piga (DCVB).-Areas: Baleares, Rosellón picòta (Grandó, Voc. rossellonès): Arán, pigota, pigıtús 'que tiene las marcas de la viruela' (Condó, Voc.

1 Deveu tenir rohin luquet, (Lo Somni de Johan Johan, ap. "Cançoner Satirich Valencià, p. 97, v. 262).

- Para Menorca, vid. también MoLL, Dial. Ciuladella, p. 429.

- Vid. Corominas, Voc. aranés.

- Asi parece que lo interpreta últimamente F. DE B. MOLL en Noles per a una valoració del lexic de Ramon Llull, Separata de "Estudios lulianos", I, fasc. 2, página 17. 
aranes; ES); Alta Ribagorza pigüeta, pigota (Ferraz, Voc. Alta Ribagorza); Espés, Bonansa, Noales, Ardanuy pigota (Haensch, p. I73); La Litera, pigota, pigotoso (Coll y Altabàs); Aragón picueta, picotoso 'picado de viruelas' (Badla, Bielsa; Pardo, Dicc.; Arnal, Alto aragones); Penarroja (Pallarès, Voc. Penarroja); Fonz (Bosch, Voc Fonz); Valderrobres (EL); Lérida (E F); Camp de Tarragona (Inf. C); Castellón (Colón, Voc. Cast.); Benicarló ( $E A$ ); Ulldecona (ER); Valencia (Escrig; M. Gadea, Voc. 50.; Inf. S); Dènia (EG); Murcia pigota, pigotoso (al este), picota (en la huerta) (G. Soriano, Voc. murciano); sardo campidanés pigotta (Wagner, Lingua sarda, 23I), Otana pigota ( $B D C, \mathrm{X}, \mathrm{x} 40)$.-Cat. antiguo: J. Roig, Spill, 9003. "Los de pochs mesos, / pobres e richs, / han per igual, / tots semblant mal: / pigotes, rosan; Torra, Thesaurus, 1653.

En general, en las áreas citadas pigota es el único vocablo existente para designar la enfermedad de la viruela. Ahora bien, en algunos sitios (Pallars, Ribagorza, Ripollés) ${ }^{1}$, pigota se aplica únicamente a los animales, especialmente a las ovejas, reservándose verola para las personas (Olot, Collsacabra) ${ }^{2}$.

Iil algunas localidades occidentales se conoce la forma del catalán central verola, pero es probable que sea de introducción reciente. In Balaguer es el término de la gente más cultivada, mientras que pigota se cousidera vulgar.

Curioso es el caso de Bellpuig (Lérida), donde se usa verola comúnmente, mieutras que pigota se aplica a la marca que deja la vacuna ${ }^{3}$.

Como hemos señalado más arriba, en catalán antiguo debía de ser un vocablo muy popular. Incluso se propagó a los dialectos sardos.

49. PIGOTA BORDA 'viruelas locas, varicela'.-Cat. cen.: verola borda.-Areas: Baleares, Valencia, Tortosa (DCVB); Benicarló (EA); Ulldecona ( $E R$ ).

Se trata de una variedad benigna de la viruela.

50. ROSA 'sarampión'.-Cat. cen. sarampió, xarampió.-Etimologfa: de rosa, entendido metafóricamente por las manchas rojizas que esta enfermedad origina ell la cara.-Areas: Mallorca, Menorca: Valencia 'alfombrilla' (M. Gadea, Voc., 5I); Castellón (Colón, Voc. Cast.);

1 R. VIOLANT I SIMIORRA, El nom, les habiluds, les funcions $i$ les malalties de des ovelles al Pallars Sobird, p. 149.

Dicc. Aguilb.

- Información del señor Figuerola, natural de aquella localidad. 
Urgel 1; Ulldecona (ER); Valderrobres (EL).-Cat. ant.: J. Roig, Spill, 9003 (vid. § 48).

In la mayor parte de estas regiones el pueblo acostumbra llamar con este nombre, rosa, el 'sarampión' y la variedad denominada en medicina 'rubeola'; como en general en el catalán central las dos se llaman sarampio. Pero en algunas localidades, como Ulldecona, Valderrobres y Balaguer, se matiza entre rosa, enfermedad que se manifiesta en las placas rojizas de la cara, y sarrampio, cuyos síntomas son unas pequeñas manchas rojas, como picaduras de pulga. Parece que aquélla es más fuerte.

Sarampió es, en catalán, vocablo moderno, quizá tomado del castellano (cfr. Moll, Supl. REW, 129o). Por lo menos no conocemos documeutación antigua. En la mayor parte del catalán oriental ha arrinconado al antiguo rosa, mientras que, en la parte occidental, éste se ha mantenido sea como término único, sea conviviendo con sarampió, gracias a referirse cada vocablo a modalidades de una misma enfermedad. Ėn Valencia, además de pallola (véase $\S 5 \mathrm{I}$ ), se conoce rosada o rosà, formado sobre rosa (Inf. S).

5I. PALLOI,A 'sarampión'.-Cat. cen. sarampio, xarampio.-Etimología: derivado de palla.-Areas: Ibiza, Valencia (DCVB; M. Gadea, Dicc. Gen.); paiola Villar del Arzobispo (Llatas).

Iin el balear el vocablo es exclusivo de Ibiza donde coexiste con rosa, que se considera una dolencia de menor gravedad. Ya hemos visto que en el resto de las Baleares se usa rosa. Es curioso que el mismo tipo léxico haya servido en aragonés y alguna localidad de Almería para designar las 'viruelas locas': pajuelas en Aragón (Pardo, Dicc.; Borao, Dicc.) y payıelas en Bédar (prov. de Almería) (DCEC). En mallorquín y catalán occidental corresponden a la llamada pigota borda (\$ 49).

52. IIOSC o IIOSCO, -A 'cegato, corto de vista'. - Cat. cen. llusco. Etim.: del lat. I u s c u s 'tuerto' (Moll, Supl. $R E W$, 2049) ${ }^{2}$.-Areas: Mallorca, Menorca, Ibiza (Inf. M.); Ulldecona (ER); Castellón (Colón, Voc. Cast.); Valencia (Escrig; M. Gadea, Dičc. Gen., Voc., 49; Inf. S); Villar del Arzobispo (Llatas); Murcia llosco, -a 'oscuro, fosco, a media luz' y enlloscarse 'oscurecerse, nublarse' (G. Soriano, Voc. murciano)._-

1 V. Surra I Bos,Dú, Calendari Folkldric d'Urgell, Barcelona, s. a., p. 230, *De pigota i de la rosa - sou singular advocat...* (Goigs a S. Magi).

- Para un estudio semasiólogico de los nombres de los defectos de la vista en las lenguas y dialectos románicos, veáse W. v. WartBURG, Die Ausdrüicke für die Fehler des Gesichtsorgans in den romanischen Sprachen und dialeklen, RDR, III, I9II, pp. 402-503. 
Cat. ant.: J. Roig, Spill, 8707, I5523; A. March, XIII: usa façés gran ab la vista molt losca» (DCVB).

Los nombres referentes a los defectos de la vista manifiestan escasa estabilidad en su significado, que fácilmente se confunde y entrecruza con el de otros nombres que designan enfermedades de la vista de carácter diferente.

L u s cus significaba en latín clásico 'tuerto, falto de un ojo'. (cf. cast. ant. y mirandés lusco con este sentido) ${ }^{1}$, pero pronto se desplazó de esta área semántica, pasando 2 a. significar 'bizco' en asturiano y valenciano ${ }^{3}$ (comp. fr. louche) y 'cegato' en catalán y balear. Iin menorquín llosc era sinónimo de 'tuerto', pero hoy sólo se aplica al que ve poco 4 . En mallorquín se usa también la expresión a les llosques 'a.oscuras'.

Pero el paralelismo de las formas del balear y del catalán occidental estriba en la evolución de la vocal tónica $i \dot{u}$ que en dichas áreas ha sufrido el cambio en 9 , normal en catalán (comp. 1 a p u $>l l o p)$, mientras que en el catalán oriental se ha mantenido como $u$, sea por influencia de llucar 'ver', sea por derivar de un étimo latino 1 ü s c u s por contaminación vocálica de 1 ux $x^{5}$.

La -o final de ambas formas, llosco, lhusco es seguramente de influencia castellana ${ }^{6}$.

53. TORT 'tuerto'.-Cat. cell. bormi.-Ftim.: del lat. t o r t u .Areas: Baleares, Reino de Valencia, Ulldecona, Calaceite, Maella, Mequinenza, Gandesa, Flix ( $A L C$, mapa nún. 293) ${ }^{7}$; Benicarló ( $\left.E A\right)$; Valderrobres (EL); Penarroja (Pallarès, Voc. Penarroja). Véase mapa núm. 7.Catalán ant.: J. Roig, Spill, I5322: "com 1 ome tort / rey entrels çechs"; Nebrija, Lexicon, I560: stort de un ull. luscus, i; cocles, itis; tort lo mateix: unoculus. i.p

Parece que el significado prístino de tort fué 'bizco', es decir, 'que tuerce la vista', y en este sentido lo tenemos documentado en el siglo xv: «tort:

1 Según G. DE Driggo, Dicc. Etim.

- Quizá ya en latín popular, según Btocir-Wartburg, Dict. Etim.

- G. DE DIEGo, Dicc. Elim. Pero en valenciano puede siguificar 'bizco' y 'miope', segin EsCRIG.

- Vid. Aclariments en BDC, II, p. 97.

- Véase J. Coroninas, Voc. aratr. y DCEC, s. v. lusco.

- Vid. P. BArnils, Fossils de la llengua, BDC, II, p. 10.

- Para el castellonense, vid. también Cor, $O N$, Voc. Cast., y para el valenciano. IiscriG; M. Gadea, Dicc. Gen. y Voc, 5I. Nuestras encuestas confirman la locallzación geográfica de este término: Dènia $(E G)$; Ulldecona $(E R)$. 


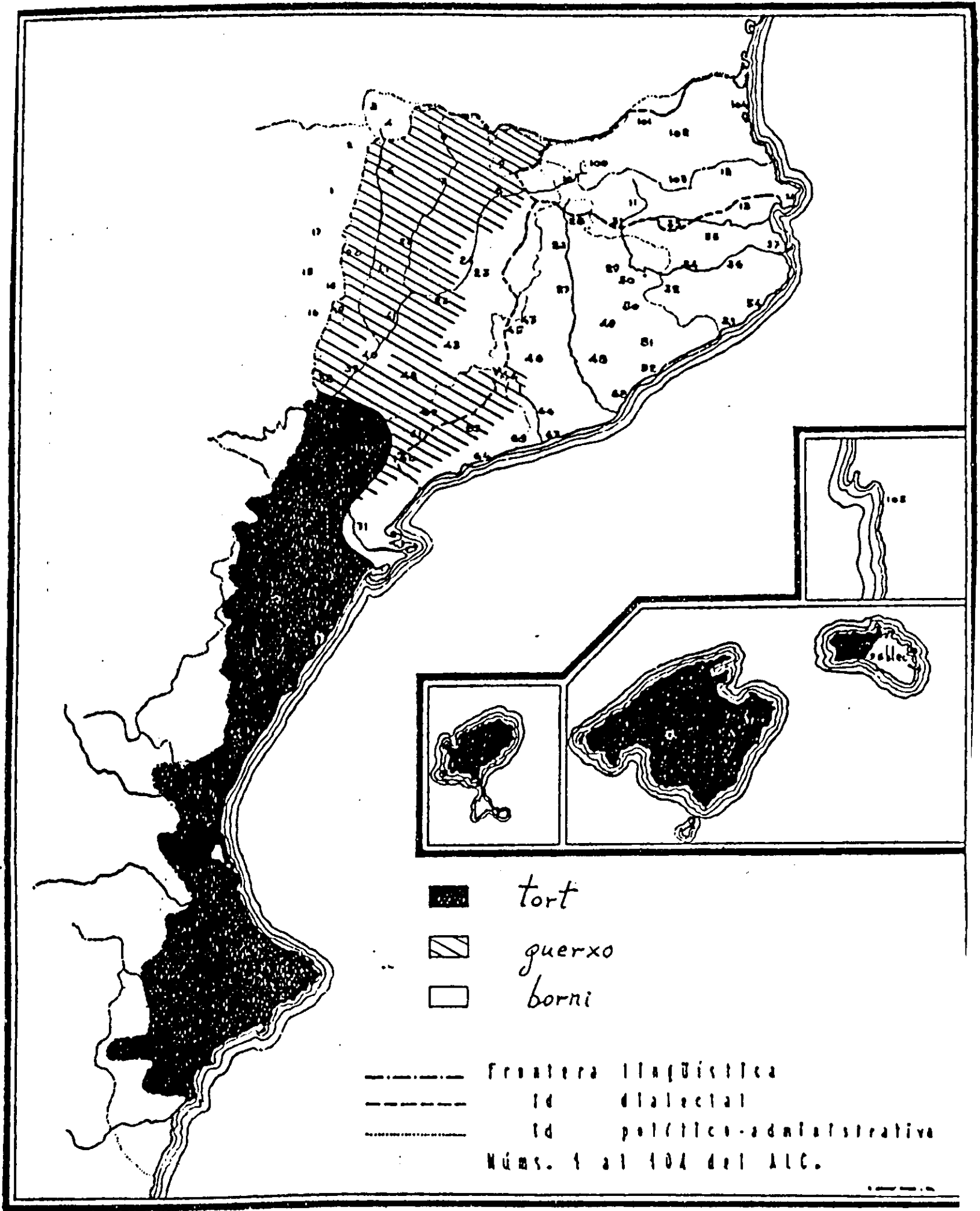

Extensión de TORI' 'tuerlo' (seguin ALC, 293) 
limus, a, um, ut limis oculis» ${ }^{1}$. Pero ya en esta época debla coexistir con tort 'tuerto', pues ya hemos visto la cita de J. Roig y del Diccionario de Nebrija. Es curioso que en el leridano se haya operado una evolución idéntica: en este dialecto occidental (véase mapa citado) al que le falta un ojo se le llama guerxo, que, en cambio, en la mayor parte del dominio catalán significa 'bizco' (< italiano guercio, procedente del germ. dwerh 'oblicuo', según $D C V B)$. Ya nos hemos referido más arriba ( $\S 46$ ) a la facilidad con que dos nombres que designan defectos visuales trasponen sus áreas semánticas.

54. MOSTELA 'roncha, equimosis' (mancha negruzca producida por extravasación de la sangre a consecuencia de un golpe).-Catalán cen. sangtraït, mula.-Etim.: del lat. $\mathrm{m}$ u $\mathrm{ste} 1 \mathrm{a}$, en sentido figurado.-Areas: Mallorca, Menorca, Tortosa, Camp de Tarragona, Vic (DCVB).

Es frecuente designar la equimosis con nombres de animales. Compárese el cat. inula con el aragonés burra. A veces se buscan otra clase de nombres descriptivos, como garroff (Ulldecona), blau (Lérida), blaïra (Benicarló).

55. PADRASTRE 'padrastro, respingón' (trocito de piel que se levanta en la parte del dedo inmediata a la uña). - Cat. cen.: repeló, desenemic, enemic.-Etim.: del lat. $p$ at $r$ a s $\mathrm{r} u$ 'padrastro (acepción primaria)', aplicado a los respingones por las molestias que ocasionan (DCV B).--Areas: Mallorca, Valencia (DCVB; M. Gadea, Voc., 50).

He aquf un vocablo con variedad de sinónimos, fruto de la exuberante imaginación popular. A los ya citados, podemos añadir grell, repel, repelo, repello, reveixi (DCVB), que ocupan distintas zonas del dominio, sin unidad en su repartición geográfica.

Padrastre suele pronunciarse, con disimilación de líquidas, padastre.

\section{Vida social y connercio.}

56. CARRERA DE SANT JAUME 'Vía láctea'--Cat. cen. camb́ de Sant Jaume. - Etim.: compuesto de carrera < lat. c a r r a ria y Sant Jaume < lat. Sa nctu J a c o m u.-Areas: Mallorca, Ibiza, Or-

1 J. ISTetre, Diccionari Calald-Llati, Venècia, I48I (ap. Dicc. Agtilo). También en este sentido lo registra el Diccionario de Nebrija: vort de ulls. strabo, strabonis, (NIiURIJA, Lexicon, 1560). 
ganyà; Pobla de Iillet la carrera de Cerdanya ( $D C V B)$. - El uso de carrera 'camino' es frecuentísimo: Muntaner, Crónica ( $D C V B$ ); R. Llull, Llibre de'Amic e Amat, ed. ENC, p. 27; F. Eiximenis, Doctrina compendiosa, ed. ENC, p. 25: "Benaventurats són tots aquells qui temen wostre senyor Déu e aquells qui van en les sues carreres»; B. Metge, Somni, ed. ENC, p. I62.

E1 uso de carrera, como término de la lengua común, se ha conservado en Mallorca, pero restringido en 'espacio de calle correspondiente a la anchura de la fachada de una casa'. Así, pues, las mujeres ragranen sa carrera» o "reguen sa carrera». En aragonés, en Benasque (Badía, Contrib.) y Bielsa (Badía, Bielsa), parece que se ha conservado también esta voz, equivaliendo a 'calle'. En cambio, en la expresión arriba apuntada ha quedado fosilizada la significación medieval de 'camino' 1.

57. MALNOM 'apodo'.-Cat. cen. motill.-Etim.: compuesto de mal y nom.-Areas: Mallorca; Ibiza (la capital; Inf. M); Valencia (Fscrig; M. Gaden, Voc., 85; Inf. S); Castellón (Colón, Voc. Cast.); Benicarló ( $E A)$; Ulldccona (ER); Lérida (EF); Viella ( $B D C, \mathrm{VI}, 30$ ).

En catalán occidental se conocen otras denominaciones: renom (Oliana) (EE), motada (Urgel, Segrià ${ }^{2}$; Benasc), mote ${ }^{3}$ (Valderrobres) (EL).

58. MENU'TS 'monedas de poco valor, calderilla'.-Fitim.: del latín m i n u $t$ u 'pequeño'. - Areas: Mallorca, Alicante ( $D C V B$ ); Ibiza (Inf. M) Dènia (EG); Valencia (Eiscrig, Voc., 85); Castellón (Colón, Voc. Cast.); Benassal (C. Salvador, Voc.); Ulldecona (ER).-Cat. ant.: Doc. año I359: "Rebérem... quatrecentes setanta nou lliures de menuts»; Doc. año I54I (DCVB).

Menuts era antiguamente el nombre genérico que se daba a los dineros de vellón de Aragón, Cataluña y Valencia. Los había de muy diversas clases: menuts barcelonesos, $m$. de la terra, $m$. doblers, $m$. de Vich, etcétera 4. En las áreas indicadas se ha conservado este nombre para aplicarlo a monedas de poco valor (calderilla) o a billetes pequeños. En Mallorca, a la calderilla se le llama también ferro, por una curiosa metoni-

- En la Segarra se ha conservado el derivado carrevada camí per on passen els ramats de bestiar que llurs pastors menen o tornen de firas (BDLLC, IX, página 234).

- Según $D C V B$.

- De influencia castellana, sin duda.

- Vease amplia información en I'. MÁrnu Y LI,OHS, Glosario hispdnico d. Numismdica, Barcelona, 1946. 
mia. En Ulldecona más vivaz que menuts es el castellanismo perretes, que toma forma masculina en Benicarló, perrets (compárese con el ibicenco canets).

59. VIDRIOLA, VEDIRIOLA 'hucha, alcancia'-Cat. cen. guardiola._litim.: de guardiola, deformado por cruce popular con vidre (DCV B).,-Areası Mallorca, Camp de Tarragona, Lérida, Vinaròs, Sueca, Xàtiva, Alicante ( $D C V B$, s. v. guardiola); Ibiza (Inf. M); Dènia (EG); Tortosa (Mestre, Voc. Tortosa); Benassal (C. Salvador, Voc.); Castellón de la Plana, Villarreal, Artana (Colón, Voc. Cast.); Benicarló (EA); Onda (Dicc. Aguiló); Murcia, (distr. de Dolores) (G. Soriano, Voc. murciano) 1.

Se trata de una deformación popular de guardiola, por contaminación de vidre, pues hay alcancías que se construyen de barro vidriado. Lladriola es otra alteración por analogía de lladre, como rodiola (Ulldecona) lo será de rodar (no de rodó, porque en esta zona se pronuncia red6, vid. § I56).

lis curioso que guardiola nparezea también en la localidad andaluza de Bacarés (Almeria) (1uf. $\Lambda$ ).

6o. A'TAÜLLAR, TAÜLLAR, occ. 'calcular a ojo la extensión de un campo, apuntar, mirar, observar', mall. TRAƯLLAR 'manejar los negocios a su modo o mezclarse en todos' (Amengual) ${ }^{2}$, 'ir de aquí allá, moverse sin parar'.-Etim.: ataiillar se ha formado, según Corominas, sobre taiilla, nombre de una medida agraria, procedente del árabe $t$ á h. u il a 'trozo de tierra'. Traiillar no es más que una alteración del mismo verbo ${ }^{3}$.-Areas: Mallorca, Poboleda (Priorat), Cerdaña, Segrià, Tortosa, Maestrat, Castellón, Valencia, Alcoi, Ribera de Xúquer ${ }^{4}$; Ulldecona $(E R)$ taillar 'divisar, distinguir'.-Cat. ant.: J. Roig, Spills; texto siglo xv (Dicc. A guiló): "lo diable que tant traulla per a perdre la nostra ànima...».

In Cerdaña y Mallorca el significado es el mismo, 'moverse, ir y venir', siendo posiblemente el significado que da Amengual una mala interpretación, como apunta Corominas. En ambas zonas se ha formado un postverbal traüll, cat. 'tràfec', cat. 'ajetreo'. Obsérvese en ellas, ade-

1 En Valencia convive con lladriola (M. GADFA, Voc., 85; Inf. S) y en Lérida y Balaguer, con guardiola $(E F, E V)$.

IJ. J. AMenguaI, Nuevo Diccionario mallorquin-casiellano-lalin, II, 1878 .

- J. Coronines, Mots calalans d'origen ardbic, BDC, XXIV, 1936, páginas 30-32.

- DCV B; J. COROMunias, $t h$.

- J. Cokoninis, id. 
más, una mayor prolongación semántica, frente a las acepciones del valenciano; más ajustaclas al significado primitivo.

61. ALMU'I' 'alnud'. - Titim.: del árabe a 1 - $111 \mathrm{u} \mathrm{d} \mathrm{d} \mathrm{.} \mathrm{-} \mathrm{Areas:} \mathrm{Ba-}$ learcs, Sopeira, Bonansa, l’ont de Situert, Sort, Calaceite, Castellón, Sueca, Ganda, Alcoi, 'Jirbena, Pego, Alicante (DC.VIB).-Cat. ant.: Ordinacions Palatines, Costums de Torlosa; doc. año 1373; J. Roig, Spill (DCV B); Llibre de Moslaçaferia, p. 42: "It que los hostalers hagen haver: almuts, punyerons e migs punyerons a la dita mesuran.

Esta palabra conoce otras variantes, por los distintos cambios fonéticos que ha sufrido el artículo árabe al-: aumut, amut, armut. Además, cono sucede a menudo con otras medidas, la capacidad varía según las comarcas.

IX. Oficios y cargos.

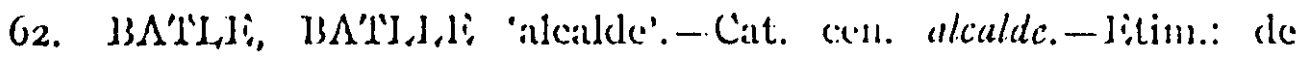
b a j a 1 u 'mozo de cucrda', 'portador (le jesus' (DCV 13). - $\Lambda$ reals: Baleares, Esterri d'Aneu, Sort, 'Tremp, Oliana, Ager, Balaguer, Borges Blanques, Alcarràs, Filix, Gandesa ( $A L C$, mapa núm. 59) ${ }^{1}$. También se registra en algunas localidades del catalín oriental.-Cat. ant. (con las acepciones medievales, naturalmente): doc. anu I248; Arnau de Vilanova; docs. años I3ro y I4 Io ( $D C V B$ ).

En catalán antiguo balle tenía el valor de 'encargado de administrar justicia', de 'gobernador de un castillo' o de 'administrador', de los que se pasó al moderno de 'alcalde'. También en la época medieval se conocla alcalde, término de origen árabe, que sufrió una evolución semántica parecida a la de ballle, al pasar de 'encargado de administrar justicia' a 'alcalde' en el sentido moderno. Pero esto no tuvo lugar hasta el siglo xvir. Es decir, que las dos palabras son de ascendencia antigua, aunque la conciencia lingüística del pueblo considera batlle como más genuino y tradicional, cosa que ocurre incluso en el catalán oriental donde no se desconoce su significado, aunque carezca de vitalidad. Sólo la coincidencia de alcalde con el término de la lengua oficial ha contribuído al éxito de su equivalente catalán, el cual ocupa todo el reino de Valencia y va ganando terreno de cada día, en el Principado, a costa del término, considerado como más castizo, batlle ${ }^{2}$.

1 Véase $\Lambda$. M. BADIA MARgarír, Alcalde. Di/usión de un arabismo en calalán. Aomenaje a Millás Vallicrosan, Barcclona, 1954, I, mapa de la p. 7r.

2 jestumimos de $\Lambda$. M. Badia margature, ob. cil.

10) 
63. CALCINER 'calero' (el que hace o vende cal). - Etim.: derivado de calcina 'cal' (hoy vivo en Alguer y Benasc, según ALC, mapa núm. 364). (DCV B).--Areas: Mallorca, Menorca, Rosellón, Ampurdán, Vall d'Aneu, Urgel, Tortosa, Maestrat, Castellón, Valencia, Xàtiva, Alcoi (DCVB) 1.Cat. ant.: İncontramos calciner 'calera, horno para la cal': Doc. año I434; y calcina 'cal': Desclut, Cronica (DCVB).

64. MURADA 'muralla'.-Cat. cen. muralla.-Etin.: derivado de mur.-Areas: Baleares, 'Tortosa ( $D C V B)$; Ulldecona (ER).-Cat. antiguo: Il $D C V B$ cita un documento antiguo, sin fijar la fecha: «car ultra que la murada de la present vila...».

65. ILAMBROIX 'pujavante' (para cortar el casco a las caballerías).-Cat. cen. botavant.-Areas: Baleares, Gandesa, Tortosa, Valencia, Sueca, Cullera, Pego, Alcoi (DCVB); Benicarló (EA) 2.-Cat. antiguo: Doc. año I437: "Quatre lambroxos de ferro petits"; Dieç, Llibre de Meniscalia (DCVB).

Juan Vhiny $C_{\text {LaR. }}$

Universidad de Barcelona. (Continuara)

1 Til testimonio de Valencia, confinmado por M. GADEA, Dicc. Gen.

- También lo citan para Valencia Escric y M. GADEA, Voc., 54.

A.-Señalamos a continuación las obras citadas con wás frecuencia, con las abreviaturas bibliográficas correspondientes:

\section{BIBLIOGRAFIA}

AL,Cover-MolL, Diccionari catald-valencid-balear (con la colaboración de M. Sanclis Guarner). Se publica desde 1930. Han salido ocho tomos y los fasciculos I54-IG2 del tomo IX (hasta resullar). $-(=D C V B)$.

Jonn Amades, Termes dialeclals de la comarca de Gandesa, Eixcursions. Noticiari de la Secció A teneu Iinciclopèdic Popular, Barcelona, II, I9r7-1919, páginas 287-201.-(= AMA ves, Termes Gandesa).

l'iejoo arnai, Cavero, Vocabulario del Allo-Aragonés (De Alquezar y pueblos próximos). C. S. I. C., Instituto Antonio de Nebrija, Madrid, 1944--(= ARNAI., Allo-Aragonds).

RAMION ARQUES I ARRUFA', Variants de la llengua catalana parlada a les Borges d'Urgell, $i$ pobles veins de la Plana, BDLLC, VI, pp. 33-40, 49-56, 69-74 85-93.-(= ARQUES, Variants Borges).

ANTonio Badía MLARgarit, Gramática histórica calalana, Barcelona, 195r.-(= BADíA, Gram. hist. cat.).

ANTONio Badfa MLARGaRtT, Contribucion al Vocabulario aragones moderno, Monografias de la Eistación de Listudios Pirenaicos, Zaragoza, 1948.- $(=\mathrm{BA}$ Dla, Contrib.). 
Antonio badfa Margarut, El habla del Valle de Bielsa, C. S. I. C., Instituto de Eistudios Pirenaicos, Barcelona, 1950.- (= BADfA, Bielsa).

Perri Barnins, Del catald de Fraga, BDC, IV, 1916, pp. 27-45.- $=$ Barnits, Cat. Fraga).

BLOCII-War'rnURG, Dictionnaire Etymologique de la Langue Frangaise, Paris, 1950, 2." éd. refondue par Wartburg.-(= BI.OCII-WARTBURG, Dict. Elym.).

JuRÓNıMO Borau, Diccionario de voces aragonesas, Zaragoza, 1908, 2." ed.- $(=\mathrm{BO}$. RAO, Dicc.).

Vicint Boscri, Vocabulari de Fonz, Anuari de l'Oficina Romànica de Lingülstica 1 Literaturan, II, 255-263.-(= Boscr, Voc. Fonz).

GIRMÁn COr ÓN DONENECH, Vocabulario castellonense. Tesis doctoral presentada a la Universidad Central de Madrid. Inédita.- $=\operatorname{CoL} 6 \mathrm{~N}$, Voc. cast. $)$.

J. Condo, Vocabulari aranès, $B D C$, III, 1915, pp. 1-27.-(=COND6, Voc. aranes $)$.

Juan Corominas, Vocabulario aranés, Barcelona, 1931.-(= Coronenas, Voc. aran.).

Jonn Coromines, El parlar de Cardos i Vall Ferrera, BDC, XXIII, 1935, páginas 24 I-33r.-(= Coromines, Cardos).

Juan CoRomnas, Diccionario critico etimológico de la lengua castellana, Madrid, 1954-1957, 4 tomos. - (= DCEC).

Diccionari Aguils. Mnterials lexicogràfics aplegats per M. $\Lambda$ Gurr.6 × Iussrur. Revisats i publicuts sota la cura de l'. Tabra $1 \mathrm{M}$. de Montoliu. Institut d'Eistudis Calalaus, J3arcelona, 8 tomos.-( $\Rightarrow$ Dicc. Aguilo).

Josf Iiscric y MARTín1iz, Diccionario Valenciano-castellano, corregido y aumentado... por una Sociedad de Literatos, bajo la dirección de Constantino LLOMBART, Valencia, 1887, 3." ed.-(= EsCRIG).

Vicente Ferraz y Castan, Vocabulario del dialecto que se habla en la Alta Ribagorza, Madrid, 193.1.-(= FERRAz, Voc. Alla Ribagorza).

VICENTE GARCfa DE DIi:Go, Diccionario etimoldgico español e hispánico, Madrid, 1955-(= DieGo, Dici. elim.).

Jonduim Garcia Grona, Vocabulari del Maestrat, Castelló, ig22 (hasta el vocablo guaja).-(= G. GIRONA, Voc.).

Justo Garcia Soruano, Vocabulario del dialecto murciano. Con un estudio prellminar y un apéndice de documentos regionales, Madrid, I932.- $=$ G. SoRIANO, Voc. Murciano).

C. Granió, Vocabulari rossellonès, "Miscel.lània Fabran, Buenos Aires, 1943, páginas $180-205 .-(=$ Grandó, Voc. rossellonds).

A. Grikra, Atlas Linguiistic de Catalunya, Barcelona, 1923-1936; 4 vols. 8 los mapas 787 a 858 del vol. V. $-(=A L C)$.

A. GRJERA, Tresor de la Llengua, de les tradicions $i$ de la Cullura popular de Calalunya, Barcelona, 1935-1947, I4 tomos.-(GruERA, Tresor).

P. E. Guarnerro, Il dialetto catalano d' Alghero, AArchivo Glottologico italiano', IX, pp. 26r-364.-(= Guarnerio. Dial. cat. Alghero).

GUNTHER HAENSCH, Beiträge zur Kenntnis des aragonesischkatalanischen Sprachgrenze im Pyrenäengebiet (undarten der oberen Ribagorza). Inaugural-Dissertation zur Errangung der Doktorwürde der Philosophischen Fakultät der Ludwig-Maximilians-Universität zu München vorgelegt... aus München, 1954. Inédita.- ( = HafissCH).

Vicliviti Lratas BuRgos, Lenguaje de Villar del Arzobispo, anales del Centro de Cultura Valencianan, XV, pp. 164-193.-(= ILATAS). 
Joaquin Marif y GadeA, Diccionario General Valenciano, Valencia, I891.-(= M. GADEA, Dicc. Gen.).

Jonquín Marti y Gadea; Vocabulario valenciano-castellano en secciones, Valencia, 1909.-(= M. Gadea, Voc.).

Bitranakdo Mantífie Mar'fíniz, Breve estudio del dialeclo enguerino, Anales del Centro de Cultura Valenciana, XV, pp. 83-87.-(= Mar'Tinrez).

I'. MItsI'RI;, Vocabulari catald de Torlosa, BDC, III, pp. 80-114.- $=$ Musirri, Voc. Torlosa).

WII,ILLL,M MEYIR-L,UI3KLi, Romanisches Elymologisches Wörlerbuch, 3. vollstäudig neubeurbeitete Auflage, Heidelberg, 1935.- $(=R E W)$.

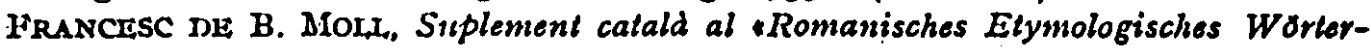
buch,, Burcelona, 1928.-(- = Mor. L, Supl. REW).

Francesci DE B. Mor,I, Estudi fonetich y lexical del dialecto de Ciutadella, Miscelánea Alcovern, Palma de Mallorca, 1932, pp. 397-460.-(= MoLI, Dial. Ciutadella).

Francisco DE 13. MOL,L, Gramática historica catalana, Madrid, 1952.-1= Mol.L, Grain. hist. cat.).

Manuer, ur Montoliu, Petil vocabulari del Camp de Tarragona, BDC, VI, 1918, pp. 38-51.-(= Montor,iU, Voc.).

G. Mozosı, L'odierno dialctto calalano di Alghero in Sardegna, Miscellanea di FIlologin e Ijinguisticn... in memorin di Napolcone Calx c Ugo Angelo Canclon, liircinze, $1886, \mathrm{pp} .3 \mathrm{r} 3-332 .-(=$ Monosi, Dial. cal. Alghero).

Lexicon latino-calalanum seu Diclionarium ALLII ANTONIr NiEDRISStNSIS... el idem

- ex catalano in latinum sermonem versum, Barcinone, 1560 (= NLBRJA, Lexicon $\times 560)$.

-Vičcok Olivs, Documents sobre el catald parlat a Sopeira (Arago), „Primer Congrís Internacional de la Llengua Catalanan, Barcelona, 1908, pp. 421-435.(= Or,IVA, Cal. Sopeira).

M. Pali,ares, Vocabulari do Penarroja (Baix Arago), BDC, IX, 1921, pp. 69-72.(= PAIrartis, Voc. Penarroja).

Jost Pardo Asso, Nuevo Diccionario etimoldgico aragonés (Voces, frases y modismos usados en el habla de Aragon), Zaragoza, 1938.-(= PARDO, Dicc.).

Carues Salvador, Petit vocabulari de Benasal, AMiscel.lània Fabra), pp. 242-263.( $=$ C. SALVADOR, Voc.).

PLTRUS TORRA, Dictionarium seu thesaurus catalano-latinus, 1653, 2.* ed.-(= ToRRA, Thesaurus).

WAI,TER VON WART'BURG, Französisches Etymologisches Wörterbuch, 1922-1950, 5 tomos (hasta la $L$ ). $-(=F E W)$.

También abreviamos el título de la colección de obras clásicas catalanas: Els Nostres Cldssics, Barcelona.- $(=E N C)$.

B.-Citamos a continuación las obras antiguas catalanas de las que hemos extraído ejemplos. Dejamos de mencionar aquellas cuyos fragmentos o citas proceden del Diccionari Calald-Valencid-Balear o del Diccionari A guild. En estas obras podrá encontrarse amplia información bibliográfica.

ANTONIO M. BaDfa MLARgarit, Regles de esquivar vocables o mots grossers o pagesivols*. Unas normas del siglo $X V$ sobre pureza de la lengua calalana. "Boletin de la Real Academia de Buenas Letras de Barcelonan, XXIII, 1950, pp. r37-1 52.

La branna dels llaturadors, ap. Canfoner Salfrich Valencid, publicado por R. MIQUEI. Y PI.ANAS, Barcelona, IgII. 
Curial e Guelfa. Iid. de R. Miguer, y Pranas. Con estudio y notas del misuo y de ANT́ÓS PAR, Barcelona, ro32.

Anioni Canals, Scifio e Anibal. De Providencia. De arra de anima. A cura de MAR'TI DE Rigurir, Col. ENC, Barcelona, 1935.

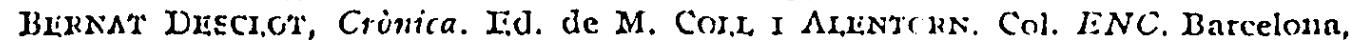
3949-1951, 5 volúmencs.

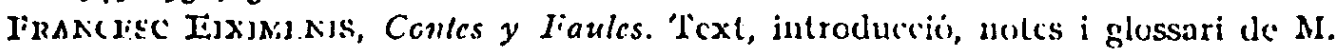
Oluvar. Col. ENC, Barcelona, 1925.

I'rancresc Iisumins, Dechina Compendiosa. Text i motació pel P. MLarif dr: marCilona, O. M. Cap., Col. ENC, Barcelona, rgay.

Efistolari del segle $X V$. Recull de cartes privades. Text, introducció, notes i glossanl per F. MartoriLi. Col. ENC. Barcelona, 1926.

Llilive de la Mostasaferia. Otdinacions de la Vila d'Igualada, segles xiv-xvr. Transctifció, notes lijstoriques i glossari d'arcaismes per G. CAsteirid I RAICH. Pröleg de J. Mercader. Igualada, 1954.

Narcís Francif, Corbatxo. Traducción de la obra de boccaccio (s. xiv). Lid. de F. DE B. MoLL, BDLLC, XVII, 1935, 5-47, 65-80, 97-132.

Ramon Liur., Llibre d'A mic e Amat. Llibre d'Ave Maria. Text per Mr. Olivar. Introduccio i notas pet Mn. Salvador GA1Mr:s. Col. LiNC, I3arcelona, 19,27.

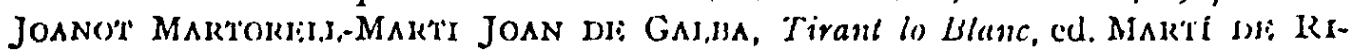
QUi:k, Warcelona, 1917.

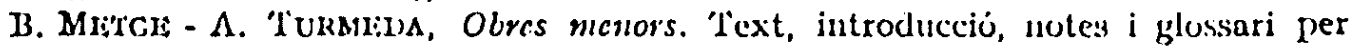
M. Or.ivak, Col. ENC, Barcelona, 1927.

B. MriTGr, Obres completes $i$ seleccio de lletres reials per cll redactades. A cura de MARTI DE RIQUER, Barcelona, I950.

B. MeTcr, Lo Scmini, Text, notes y glossari de Josep M.a de Casacunirta. Introducció de LL. NiCor,AU D'Or,Wer, Col. ENC, Barcelona, I924.

Procés de les Olives, ap. Canf̧oner Satirich Valencid.

Jaume Roig, Llibre de les dones o Spill. 'Text, introduccio, notes i glossari per F. ALMEI, I VIVES. Col. ENC, Barcelona, I928.

JaUme Roig, Spill o libre de concells. Ed. de R. Mrquir, y Pranas, Barcelona, I929-1950, 2 volúmenes.

Recull de Eximplis e Miracles. Estampado bajo la dirección de Mr. AgurLó. 3arcelona, $188 \mathrm{r}, 2$ volúmenes.

Lo Somni de Johan Johan, ap. Callfoner Satirich Valencid.

$V i d a$ de Sant Anthiogo melge y mdrtir (obra del s. Xv, publicada en el xvI). 'Biblioteca Catalana Populari, Barcelona, 18go. 